\title{
Navigating the garden of forking paths for data exclusions in fear conditioning research
}

\section{Tina B Lonsdorf ${ }^{1 *}$, Maren Klingelhöfer-Jens ${ }^{1}$, Marta Andreatta ${ }^{2,3}$, Tom Beckers ${ }^{4}$, Anastasia Chalkia ${ }^{4}$, Anna Gerlicher ${ }^{5}$, Valerie L Jentsch ${ }^{6}$, Shira Meir Drexler ${ }^{6}$, Gaetan Mertens ${ }^{7}$, Jan Richter ${ }^{8}$, Rachel Sjouwerman ${ }^{1}$, Julia Wendt ${ }^{9}$, Christian J Merz}

${ }^{1}$ Department of Systems Neuroscience, University Medical Center Hamburg Eppendorf, Hamburg, Germany; ${ }^{2}$ Department of Psychology, Biological Psychology, Clinical Psychology and Psychotherapy, University of Würzburg, Würzburg, Germany; ${ }^{3}$ Instutute of Psychology, Education \& Child Studies, Erasmus University Rotterdam, Rotterdam, Netherlands; ${ }^{4}$ Centre for the Psychology of Learning and Experimental Psychopathology and Leuven Brain Institute, KU Leuven, Leuven, Belgium; ${ }^{5}$ Faculty of Social and Behavioural Sciences, Programme group Clinical Psychology, University of Amsterdam, Amsterdam, Netherlands; ${ }^{\circ}$ Institute of Cognitive Neuroscience, Department of Cognitive Psychology, Ruhr University Bochum, Bochum, Germany; ${ }^{7}$ Department of Psychology, Utrecht University, Utrecht, Netherlands; ${ }^{8}$ Department of Physiological and Clinical Psychology/ Psychotherapy, University of Greifswald, Greifswald, Germany; ${ }^{9}$ Biological Psychology and Affective Science, University of Potsdam, Potsdam, Germany

Abstract In this report, we illustrate the considerable impact of researcher degrees of freedom with respect to exclusion of participants in paradigms with a learning element. We illustrate this empirically through case examples from human fear conditioning research, in which the exclusion of 'non-learners' and 'non-responders' is common - despite a lack of consensus on how to define these groups. We illustrate the substantial heterogeneity in exclusion criteria identified in a systematic literature search and highlight the potential problems and pitfalls of different definitions through case examples based on re-analyses of existing data sets. On the basis of these studies, we propose a consensus on evidence-based rather than idiosyncratic criteria, including clear guidelines on reporting details. Taken together, we illustrate how flexibility in data collection and analysis can be avoided, which will benefit the robustness and replicability of research findings and can be expected to be applicable to other fields of research that involve a learning element.

\section{Introduction}

In the past decade, efforts to understand the impact of undisclosed flexibility in data collection and analysis on research findings have gained momentum - for instance in defining and excluding 'outliers' (Simmons et al., 2011). This flexibility has been referred to as 'researcher degrees of freedom' (Simmons et al., 2011) or 'the garden of forking paths' (Gelman and Loken, 2013) to reflect the fact that each decision during data processing and/or analysis will take the researcher down a different 'path'. Importantly and concerningly, these different paths can lead to fundamentally different end-points (i.e., results and associated conclusions) despite an identical starting point (i.e., raw data) (Silberzahn et al., 2018). Often, researchers take a certain path without malicious intent to obtain 
favorable results (e.g., 'p-hacking'; Head et al., 2015): the decision to follow a certain path may be based on unawareness of alternative paths (due to lack of specific background knowledge) or the researcher following the most obvious path from an individual perspective. The latter is influenced by the scientific environment, the research question at stake or practices previously published by researchers in the field.

Admittedly, there is substantial ambiguity in what constitutes 'the best decision' for data analysis, and none of the available options may be necessarily incorrect (Simmons et al., 2011; Silberzahn et al., 2018). More precisely, different paths in the garden of forking paths may be more or less appropriate for different research questions, experimental designs, outcome measures or samples. Consequently, it is notoriously difficult for researchers, particularly those new to a field, to make informed and hence appropriate decisions. As a matter of fact, it is difficult to anticipate the number of different paths available and the consequences of choosing one over the other, or to come up with facts that truly justify choosing one path over the other - even for experts in a field. However, simply choosing a particular path because others chose it before (i.e., adopting published exclusion criteria) can also be highly problematic, as decisions often hinge on study-specific characteristics that do not invariantly apply to other studies.

We argue that it is important to raise awareness to this issue. Specifically, we think that it is critical to discuss both the rationale behind and the consequences associated with taking different analytical paths in general and in specific sub-fields of research. Here, we exemplarily take up this discussion for human fear conditioning research as a case example for tasks with a learning element grounded in recent discussions in science in general (Flake and Fried, 2019; John et al., 2012) and in fear conditioning research specifically (Lonsdorf et al., 2017; Lonsdorf et al., 2019). Fear conditioning is a typical paradigm employed to study (emotional) learning and memory processes with a particularly strong translational perspective (Lonsdorf et al., 2017; Vervliet et al., 2013). Questions addressed in the field of human fear conditioning are often concerned with consolidation, retrieval, generalization or modification of conditioned responses. Hence, it has often been claimed that the study of these processes requires the acquisition of a robust conditioned response as a precondition. Therefore, participants are often (routinely) excluded from analyses if they appear to not have learned ('non-learners') or not have been responsive to the experimental stimuli ('non-responders') during fear acquisition training, in which one conditional stimulus (CS+) predicts an upcoming aversive unconditioned stimulus (US) and another conditional stimulus does not (CS-) (Lonsdorf et al., 2017; Pavlov, 1927).

Critically, 'non-learning' is most often defined as a failure to show discrimination between the CS + and CS- in skin conductance responses (SCRs) - the most common outcome measure in the field (Lonsdorf et al., 2017). This practice may seem trivial at first glance and has been referred to as exclusion of 'non-learners', 'performance-based exclusion' or even 'exclusion of outliers'. Yet, defining a set of characteristics to identify individuals who 'did not learn' is operationalized in very heterogeneous ways across studies. The same applies to the criteria that determine what constitutes a' non-responder' during fear acquisition training.

In addition to the heterogeneity in operationalization, other problems of performance-based exclusion of participants are worth noting: definitions of 'non-learners' are typically based on SCRs only (for exceptions see Ahmed and Lovibond, 2019; Oyarzún et al., 2019) and 'non-learners' are typically excluded from all analyses, that is, all experimental phases and outcome measures of a study. As SCRs are not a pure measure of either learning or fear, but rather reflect arousal levels (Hamm et al., 1993) that serve as proxies for fear learning, classification into 'learners' and 'nonlearners' on the basis of this single outcome measure may induce substantial sample bias. First, defining 'non-learning' on one single outcome measure, such as SCRs, ignores the fact that successful CS+/CS- differentiation may be present in other outcome measures (Hamm et al., 1993) such as fear potentiated startle (FPS) or ratings of fear and contingencies (i.e., cognitive awareness of the CS +/US contingencies). As such, 'non-learning' as defined on a single outcome measure such as SCRs cannot comprehensively capture 'non-learning'. Second, the level of responding in SCRs and CS+/ CS- discrimination has been shown to be associated with a vast number of individual difference factors (Lonsdorf and Merz, 2017; Boucsein et al., 2012) such as age and sex (for a discussion see Boucsein et al., 2012), ethnicity (Alexandra Kredlow et al., 2017; Boucsein et al., 2012), genetic make-up (Garpenstrand et al., 2001), use of oral contraceptives (Merz et al., 2018b) or personality traits (Naveteur and Freixa I Baque, 1987). Consequently, excluding participants from an 
experiment as 'non-learners' may pre-select specific sub-samples and thus may thus severely hamper the generalizability and interpretation of the findings. Importantly, this practice may be a threat to and a limitation of the clinical translation of findings because it potentially leads to the selective exclusion of specific and highly relevant sub-groups. In fact, a recent meta-analysis suggests that patients suffering from anxiety disorders show overgeneralization of fear responding, which is enhanced when responding to the CS- (Duits et al., 2015), which may lead to reduced CS+/CS- discrimination if the response to the CS+ is comparable.

The concerns discussed above are merely based on theoretical considerations. Below, we aim to address the important and controversial topic of exclusion of 'non-learners' and 'non-responders' in human fear conditioning research empirically. We set out to provide an overview and inventory of the exclusion criteria that are currently employed in the field by means of a systematic literature search following PRISMA guidelines (Moher et al., 2009), covering a publication period of six months. Importantly, we distinguish between 'non-learners' (based on task performance, that is, CS +/CS- discrimination) and 'non-responders' (based on a lack of responsiveness) as assessed using SCRs. We expect the identified criteria for 'non-learners' and 'non-responders' to be characterized by noticeable heterogeneity (thus allowing for considerable researcher degrees of freedom) across studies. We thus aim to (1) raise awareness and (2) illustrate the impact of applying different exclusion criteria features (i.e., forking paths) on results and interpretation through case examples exemplified by the re-analyses of existing data sets. Finally, we aim to (3) provide

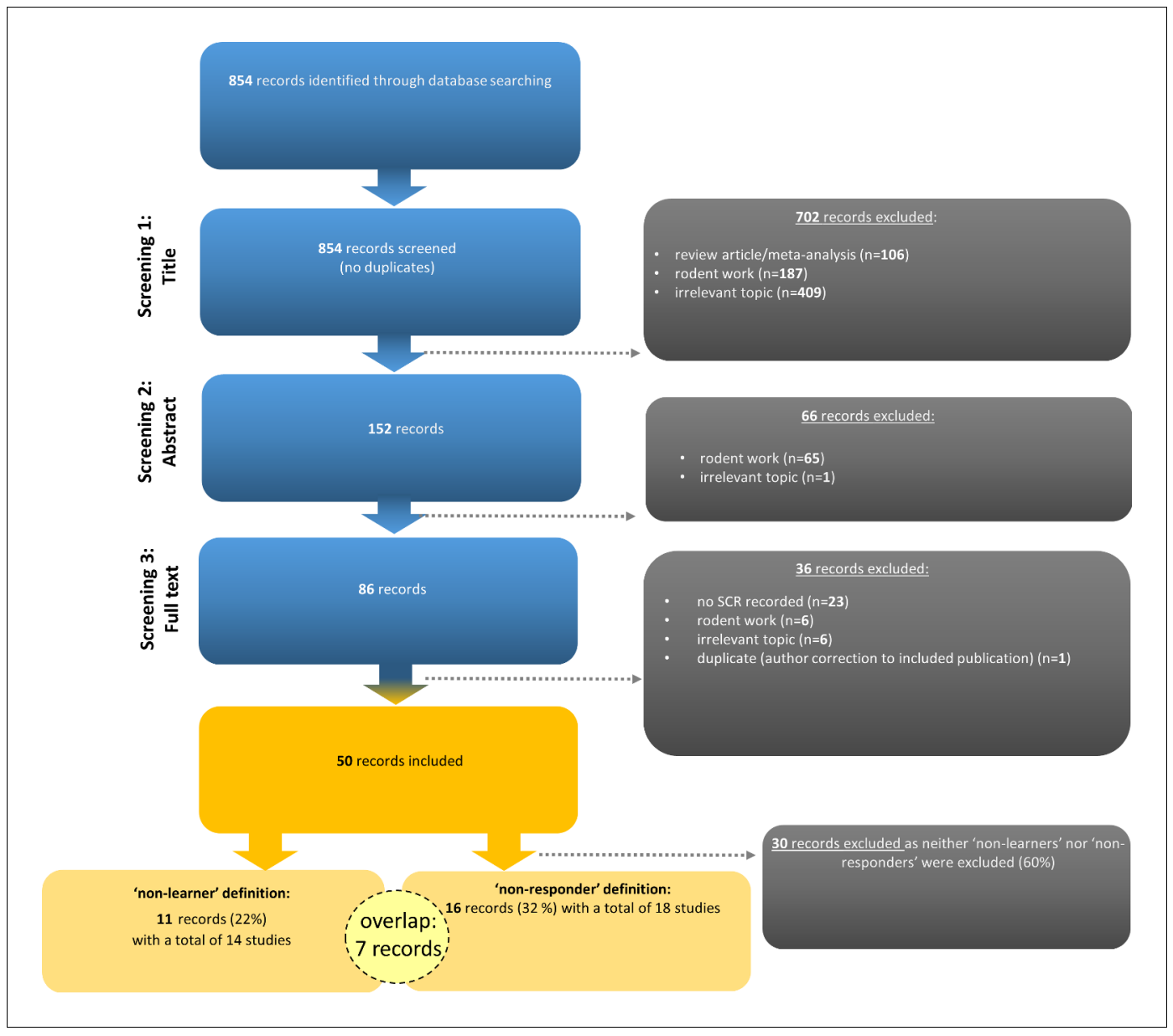

Figure 1. Flow chart illustrating the selection of records according to PRISMA guidelines (Moher et al., 2009). Note that seven records (14\%) employed the definition and exclusion of both 'non-learners' and 'non-responders'. Examples of irrelevant topics included studies that did not use fear conditioning paradigms (see https://osf.io/ uxdhk/ for a documentation of excluded publications). 


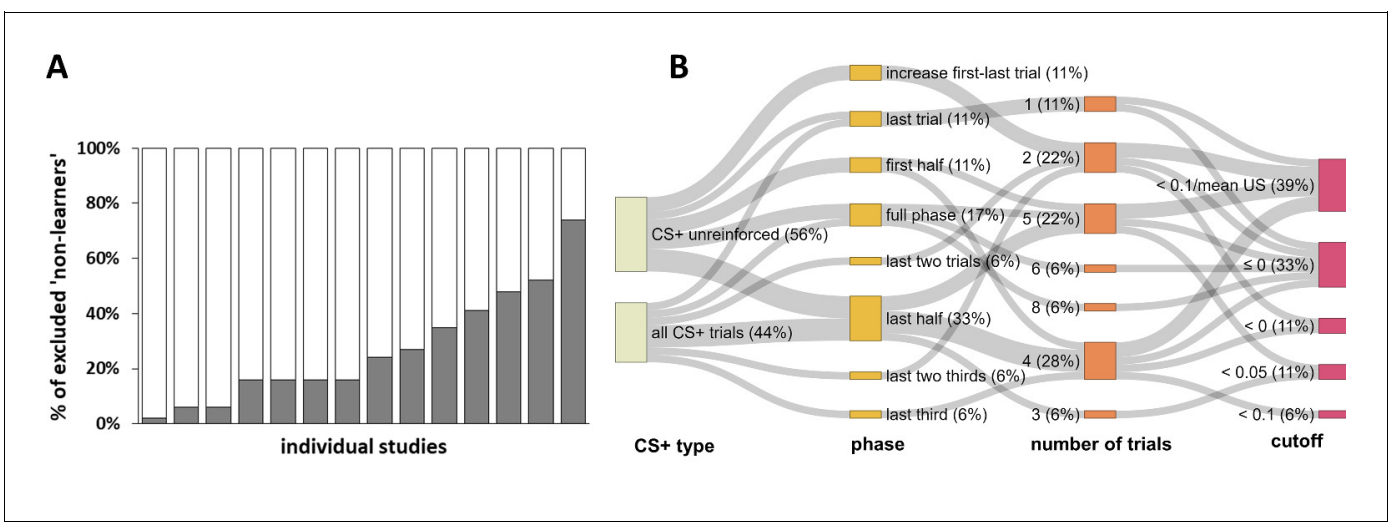

Figure 2. Graphical illustration of the percentage of 'non-learners' and forking path analysis across studies. (A) Illustration of the percentage of participants excluded ('non-learners') based on SCR CS+/CS-discrimination scores across studies included in the systematic literature search (note that these 14 individual studies are derived from 11 different records, as three records reported two individual studies each). Please note that some studies excluded participants on the basis of 'non-learning' as well as 'non-responding' (cf. Figure 1), and hence the percentages displayed here do not necessarily map onto the percentage of total participants excluded per study. Also note that the study with the highest percentage of excluded participants (i.e., 74\%) reported the percentage of excluded participants as a single value that included 'non-learners' and 'non-responders'. This study is only included here because the largest proportion of exclusions can be expected to result from 'non-learning'. (B) Sanky plot showing the 'forking paths' of performance-based exclusion of participants as 'non-learners', illustrating differences in the experimental phase, number of trials, the SCR CS+/CS- discrimination score in $\mu \mathrm{S}$ used to define a 'non-learner', the CS+ type considered (illustrated as the nodes in graded colors) and their combinations used to define 'non-learners' across studies. Path width was scaled in relation to frequency of the combinations. Note that for some 'nodes' the percentages do not add up to $100 \%$ because of rounding.

methodologically informed, evidence-based recommendations for future studies with respect to defining and handling 'non-learners' and 'non-responders'.

\section{Results}

\section{Definition of performance-based exclusion of participants ('non- learners') and number of participants excluded across studies}

Slightly fewer than one fourth of the records (i.e., 22\%; 11 out of 50 records comprising 14 individual studies as three records reported two studies each) included in the systematic literature search employed performance-based exclusion of participants (i.e., SCR 'non-learners', Figure 1).

Strikingly, every single one of these records used an idiosyncratic definition to define 'non-learners', yielding a total of eleven different definitions in the short period of six months (see Appendix 1-table 1). The percentages of excluded participants varied from $2 \%$ to $74 \%$ (Figure $2 \mathrm{~A}$ ) of the respective study sample. Definitions differed in i) the experimental (sub-)phases to which they were applied (i.e., whether the full phase or only the first half, second half or even single trials were considered), ii) the number of trials that the exclusion was based on (varying between one and eight single trials), iii) the CS+/CS- discrimination cutoff applied (varying between $<0 \mu S$ and $<0.1$ $\mu \mathrm{S}$ ), and iv) the CS+ type (only non-reinforced or all CS+ trials) considered. The different forking paths and their frequency resulting from these combinations are displayed in Figure 2B.

The cutoff for CS+ versus CS- discrimination used to identify a 'non-learner' varied between $<0$ $\mu \mathrm{S}$ and $<0.1 \mu \mathrm{S}$, with most records excluding participants as 'non-learners' if they showed either a negative discrimination $(<0 \mu \mathrm{S})$ and/or no discrimination $(\leq 0 \mu \mathrm{S})$. These criteria apply if the SCR amplitude in response to the CS- was higher than and/or equal to the amplitude elicited by the CS + . Furthermore, most records required this criterion to be fulfilled only during the last half or the full fear acquisition training phase. Of note, the number of trials included in the same 'phase' category is contingent on the experimental design and hence does not represent a homogeneous category 


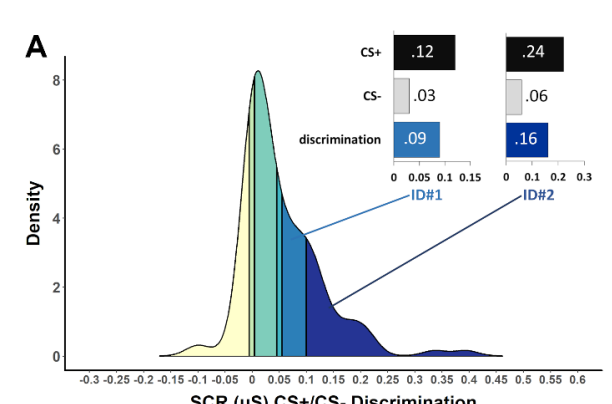

$\mathrm{SCR}(\mu \mathrm{S}) \mathrm{CS}+/ \mathrm{CS}$ - Discrimination

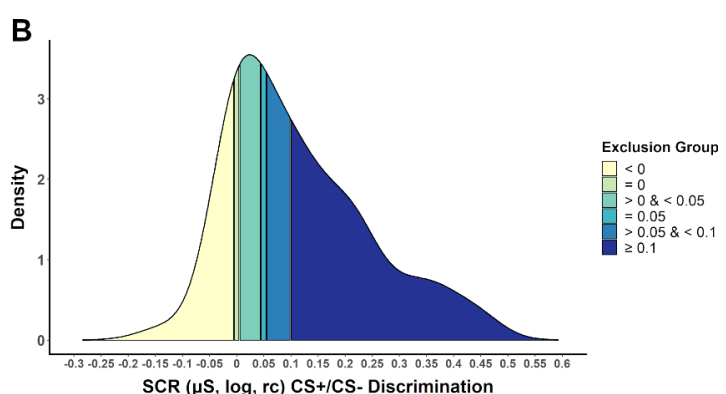

$S C R(\mu S, \log , r c) C S+/ C S$ - Discrimination

Figure 3. Density plots illustrating the frequency of CS+/CS- discrimination scores in a sample of $N=116$ (Data set 1) based on the last half of the acquisition phase (including 7 CS+ and 7CS-, 100\% reinforcement rate) for (A) SCR raw data and (B) logarithmized and range-corrected ( $r$; individual trial SCR/SCR max_across_all_trials) SCR data (as it is typically not reported to which data exclusion criteria are applied). Color coding (yellow to blue) illustrates which part of the sample would be excluded when applying the performance-based exclusion criteria (i.e. CS+/ CS- discrimination) as identified by the systematic literature search. Panel (A) also illustrates two case examples (ID\#1 and ID\#2) that differ in SCR amplitudes but importantly show the same discrimination ratio between CS+ and CS- (4:1). These two case examples illustrate that high CS+/CS- discrimination cutoffs favor individuals with high SCR amplitudes to remain in the final sub-sample. Data are based on a re-analysis of an unpublished data set recorded in the fMRI environment (Klingelhöfer-Jens M., Kuhn, M. and Lonsdorf, T.B.; unpublished).

The online version of this article includes the following figure supplement(s) for figure 3 :

Figure supplement 1. Percentages of participants excluded (Data set 1) when employing the different CS+/CSdiscrimination cutoffs (as identified by the systematic literature search and graphically shown in Figure $3 B$ ) which are illustrated as density plots in Figure 3.

('last half' may include five trials for one study comprising 10 trials in total but 10 trials for a different study employing 20 trials in total.

\section{Applying the identified performance-based exclusion criteria to existing data: a case example}

We applied the identified cutoff criteria to an existing data set (Data set 1) to exemplify the part of the sample that would be excluded when applying different cutoff criteria (shown in different colors from yellow to dark blue in Figure 3) based on the most frequently used phase restriction: the last half of fear acquisition training. $C S+/ C S$ - discrimination was calculated on the basis of raw $(A)$ or log-transformed, range-corrected (log, rc) scores (B), because it is not usually reported which data are used to classify 'learners' vs. 'non-learners'. Strikingly, the proportion of participants that are excluded is higher when CS+/CS- discrimination is calculated on the basis of raw data rather than log-transformed and range-corrected data (despite employing the same criteria) in particular for the highest 'non-learner' $<0.01 \mu \mathrm{S}$ cutoff $(76.7 \%$ versus $52.6 \%$, respectively) (see Figure 3 -figure supplement 1 for details).

In addition, we included a case example of two hypothetical individuals that differ in raw SCR amplitudes (ID\#1: low and ID\#2: high), but importantly show the same discrimination ratio (4:1) between CS+ and CS-(see Figure 3A). These two case examples illustrate that high CS+/CS- discrimination cutoffs, such as excluding individuals with discrimination scores $<0.1 \mu \mathrm{S}$ as 'non-learners', favor individuals with high SCR raw amplitudes.

Unsurprisingly, the exclusion group defined by a CS+/CS- discrimination cutoff $<0 \mu S$ showed inverse discrimination ( $C S->C S+$, not significant in raw SCRs [ $p=0.117$ ]; significant in log, $r c$ SCRs [ $=0.021]$ ). Strikingly and more importantly, most cumulative exclusion groups, as established by defining 'non-learners' by the CS+/CS- discrimination different cutoffs in SCRs in the literature, in fact show statistically significant CS+/CS- discrimination (see Appendix 2 for details and a brief discussion).

Note that despite the different color coding, which serves illustrative purposes only, the groups are in practice cumulative. More precisely, the groups illustrated by lighter colors are always 


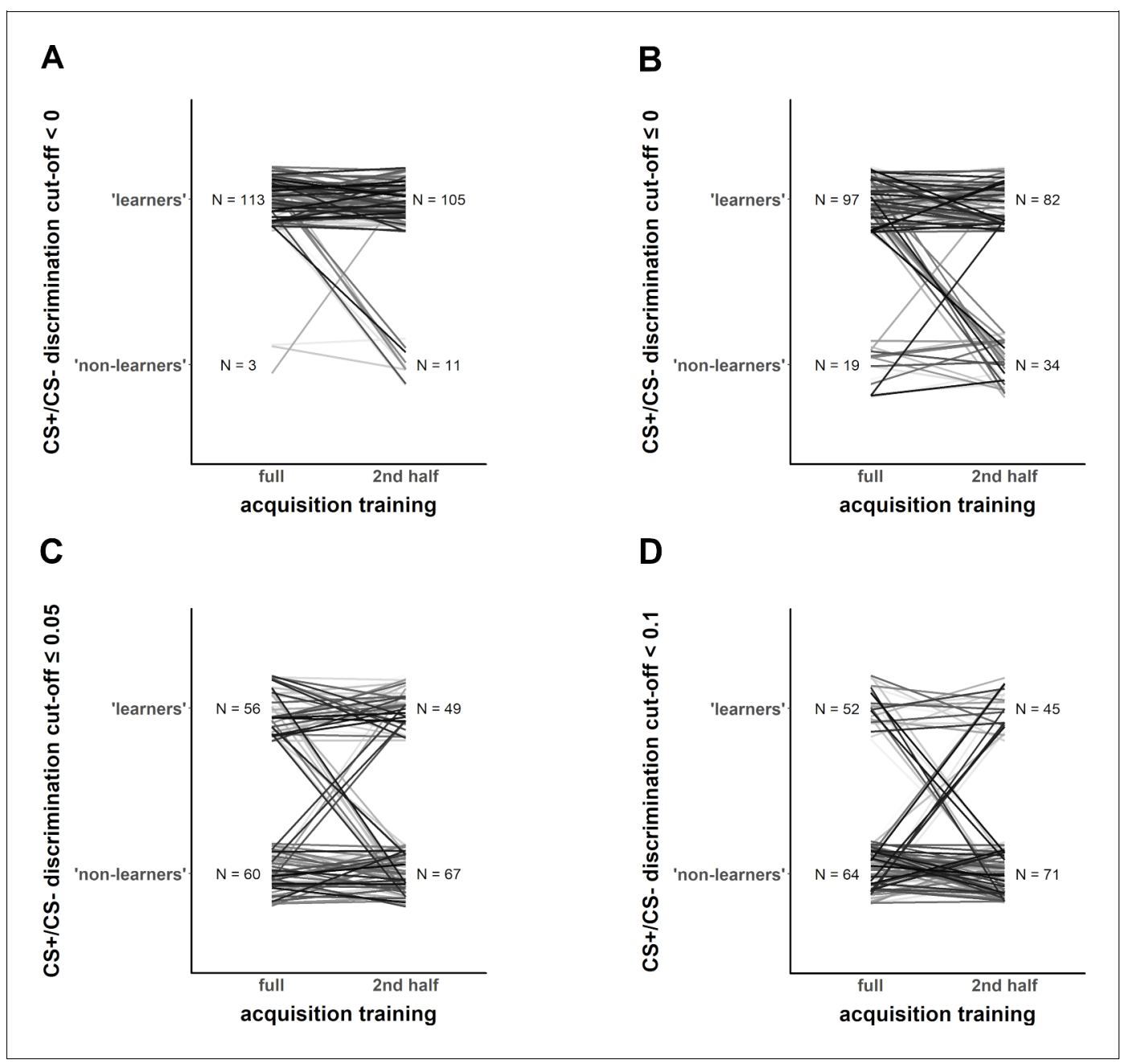

Figure 4. Exemplary illustration of individuals (Data set 1) that switch from being classified as 'learners' vs. 'nonlearners' depending on the different CS+/CS- discrimination cutoff level (panels A-D), when calculation of CS+/ CS- discrimination is based on either the full fear acquisition phase or the second half of the fear acquisition training (left and right part of each panel, respectively).

The online version of this article includes the following figure supplement(s) for figure 4:

Figure supplement 1. Bar plots (mean $\pm \mathrm{SE}$ ) on which the superimposed individual data points show $C S+$ and CS- amplitudes (of raw SCR values) and CS+/CS- discrimination in (A) fear ratings and (B) SCRs raw values in the group of 'non-learners', as exemplarily defined for this example as a group consisting of individuals in the two lowest SCR CS+/CS- discrimination cutoff groups (i.e., $\leq 0)$ in Data set 1.

contained in the darker colored groups when applying the respective cutoffs. For example, the group excluded when employing a cutoff of $<0.1 \mu \mathrm{S}$ (mid blue) also comprises the groups already excluded for the lower cutoffs of $=0.05 \mu \mathrm{S}$ (light blue), $<0.05 \mu \mathrm{S}$ (turquoise), $=0 \mu \mathrm{S}$ (light green) and $<0 \mu \mathrm{S}$ (yellow). For illustrative purposes, the different groups are treated as separate groups in this figure.

\section{Exploratory analyses of consistency of classification ('learners' vs. 'non- learners') across outcome measures and criteria employed}

The convergence of non-discrimination across different outcome measures was investigated by testing for $\mathrm{CS}+/ \mathrm{CS}$ - discrimination in fear ratings in individuals with different amounts of CS+/CS- discrimination in SCRs as defined by the criteria described above. In fact, individuals with nonsignificant and inverse CS+/CS- discrimination (i.e., $\leq 0 \mu \mathrm{S}$ ) in SCRs showed significant CS+/CS- discrimination in fear ratings $\left(t_{31}=9.69\right.$, $p_{\text {bonf_corr }}<0.000000001, d=1.71$, see Figure 4-figure 


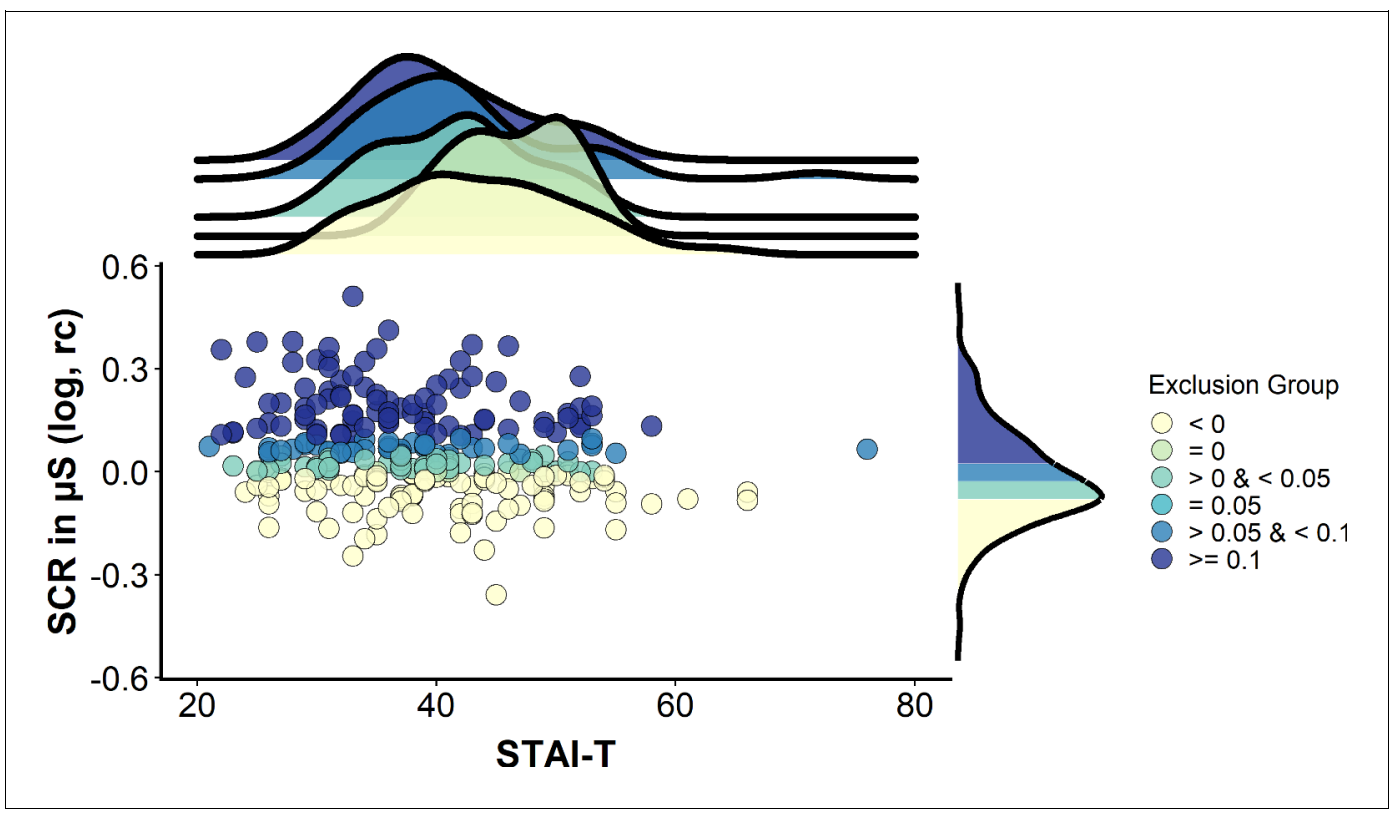

Figure 5. A case example illustrating potential sample bias induced by excluding individuals on the basis of $\mathrm{CS}+/$ CS- discrimination scores (based on logarithmized, range-corrected ( $r c$ SCR data). Scatterplot illustrating the association between trait anxiety (measured via the trait version of the State-Trait Anxiety Inventory, STAI-T) and CS+/CS- discrimination scores in a sample of $N=268$ (Data set 2). Color coding (yellow to blue) illustrates which part of the sample would be excluded when applying the performance-based exclusion criteria (i.e. CS+/CSdiscrimination) as identified by the systematic literature search. Note that within this sample, no individuals were identified with CS+/CS- discrimination equaling $0.05 \mu \mathrm{S}$. The upper panel illustrates densities for trait anxiety for the different CS+/CS-discrimination groups. The rightmost panel illustrates the density for CS+/CS- discrimination in the full sample. Data are based on a re-analysis of a data set recorded in the behavioral environment (Schiller et al., 2010). Note that despite the different color coding, which serves illustrative purposes only, the groups are in practice cumulative. More precisely, the groups illustrated by lighter colors are always contained in the darker colored groups when applying the respective cutoffs. For example, the group excluded when employing a cutoff of $<0.1 \mu \mathrm{S}$ (mid blue) also comprises the groups already excluded for the lower cutoffs of $=0.05 \mu \mathrm{S}$ (light blue), $<0.05 \mu \mathrm{S}$ (turquoise), $=0 \mu \mathrm{S}$ (light green) and $<0 \mu \mathrm{S}$ (yellow). For illustrative purposes, the different groups are treated as separate groups in this figure.

supplement 1). Importantly, all cumulative exclusion groups showed significant CS+/CS- discrimination in fear ratings (all $p$ 's $<0.002$, see Appendix 3-table 1).

We also illustrate (Figure 4) that the classification as 'learners' and 'non-learners' changes if two features (CS+/CS- discrimination cutoff and full vs. last half of acquisition training phase) of the criteria are changed (as illustrated in their full variation in Figure 2B).

\section{The potential sample bias with respect to individual differences induced by employing different performance-based exclusion criteria: a re- analysis of existing data and a case example}

Regarding the impact of performance-based exclusion on the pre-selection for certain individual differences, Figure 5 shows that the distributions of trait anxiety were shifted to the left (i.e., towards lower scores) with higher SCR CS+/CS- discrimination cutoffs. More precisely, this means that, in this sample, highly anxious individuals display smaller CS+/CS- discrimination in SCRs, and that excluding individuals who display low discrimination scores will lead to the exclusion of anxious individuals.

In fact, we observed a main effect of 'Exclusion group' on trait anxiety score $\left(F_{[4,263]}=219.2\right.$, $p<0.001, \eta_{P}^{2}=0.77$ ). All exclusion groups (corresponding to the color coding in Figure 5) differ significantly from each other in their trait anxiety scores (all $p_{\text {bonf_corr }} \leq 0.001$ ), except for the group that did not show any CS + /CS- discrimination $(=0 \mu \mathrm{S}$, light green, however $n=6$ only), which showed significantly higher trait anxiety scores (mean \pm SD STAI score: $43.8 \pm 6.1$ ) than the group 


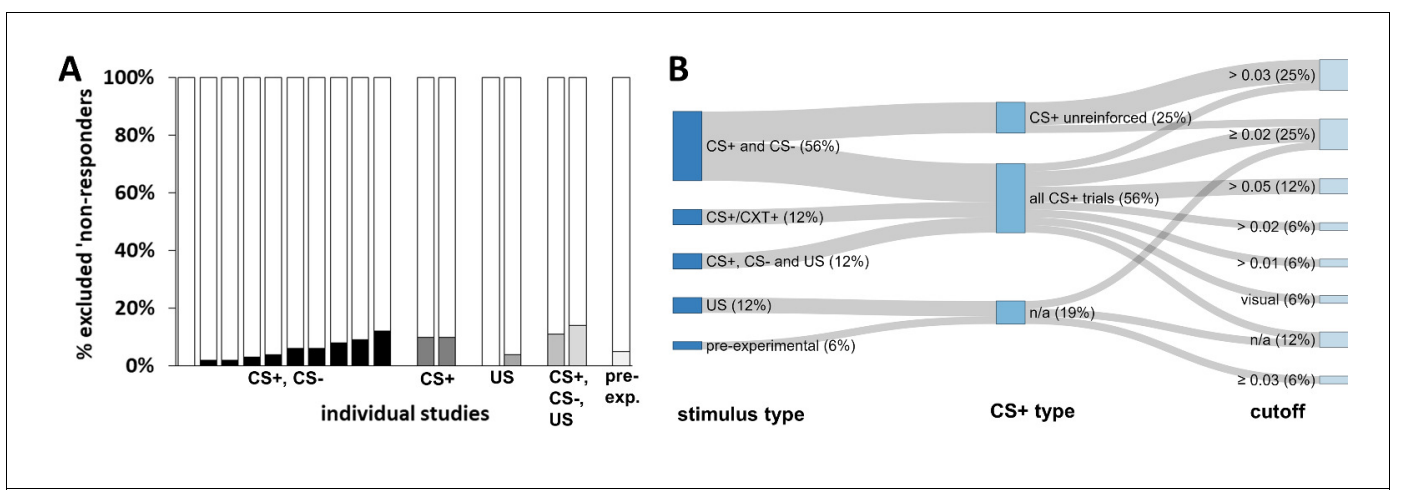

Figure 6. Graphical illustration of the percentage of 'non-responders' and forking path analysis across studies. (A) Illustration of the percentage of participants excluded from each study as a result of ' SCR non-responding' to (i) the conditioned stimuli (i.e., CS+ and CS-), (ii) the US, (iii) the CS+ (which also comprises a study that used the CXT+, i.e. context), (iv) the CS+, CS- and US or (v) a pre-experimental test. Note that these 18 individual studies are derived from 16 different records, two of which included two different studies that used the same criteria. Note that some studies excluded participants on the basis of 'non-learning' as well as 'non-responding', and hence the percentages displayed here do not necessarily map onto the percentage of total participants excluded from each study. Also note that a single study (Schiller et al., 2018) is not included in this visualization because it reported \% 'non-learners' and \% 'non-responders' as a single value. This value has been included in the visualization of 'non-learners' (Figure 2) as these are expected to represent the largest proportion. (B) Sanky plot illustrating the stimulus type (pre-experiment refers to determination of 'responding' in an unrelated phase prior to the experiment), the minimally required response amplitude in $\mu \mathrm{S}$ (note that 'visual' refers to visual inspection of the data without a clear-cut amplitude cutoff, NA refers to no criterion applied) illustrated as the nodes in graded colors and their combinations that lead to classification as a 'non-responder'. Path width was scaled in relation to frequency of the combinations. Note that for some 'nodes' the percentages do not add up to $100 \%$ because of rounding.

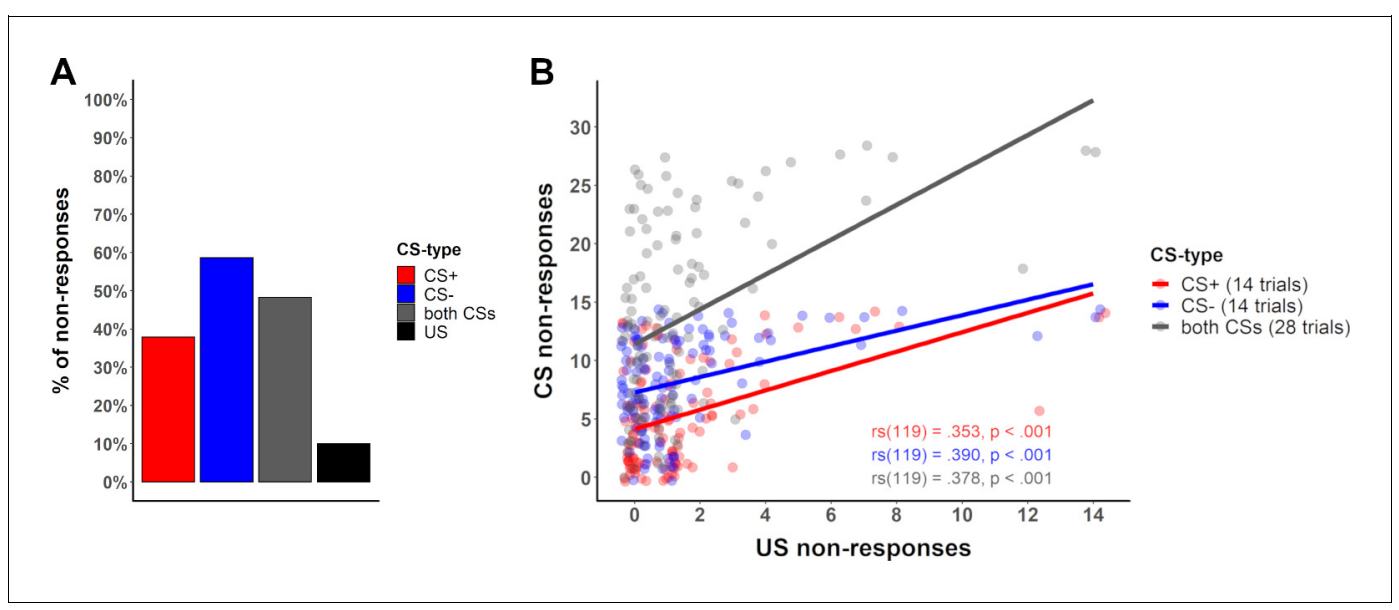

Figure 7. Percentage of no-responses across stimuli and correlation between CS and US non-responses. (A) Bar plot displaying the number of 'non-responses' to the CS+, CS-, across both CS and to the US across all participants in Data set 1 (see Appendix 4-table 1 for percentages across different data sets). (B) Scatterplot illustrating the number of 'non-responses' (i.e., zero-responses, here defined by an amplitude $<0.01 \mu \mathrm{S}$ ) to the US presentations (total of 14 presentations) and the CS+ (red) and CS- (blue) responses (14 presentations each) for each participant in Data set 1. For completeness sake, 'non-responses' across CS types are illustrated in gray (CS+ and CS- combined, total of 28 presentations). Lines illustrate the Spearman correlation (rs) between 'nonresponses' to the US and 'non-responses' to the CS+, CS- and both CS, with corresponding correlation coefficients (font color corresponds to CS type) included in the figure. 
with the largest CS $+/ C S$ - discrimination only (i.e., $\geq 0.1 \mu \mathrm{S}$, dark blue, $n=88$, mean \pm SD STAl score: $36.6 \pm 8.5$, p ponf_corr $\leq 0.001, \mathrm{Cl}[0.133$ to 0.279$])$. Nevertheless, trait anxiety scores in this group (light green) were not significantly larger than those in the group with the negative discrimination (i. e., $<0 \mu \mathrm{S}$, yellow, $n=89$, mean \pm SD STAl score: $40.5 \pm 9.7$, p ponf_corr $=0.10, \mathrm{Cl}[-0.004$ to 0.142$]$ ), the group with a small discrimination score (i.e., $>0 \mu \mathrm{S}$ but $<0.05 \mu \mathrm{S}$, light blue, $n=43$, mean $\pm S D$ STAl score $37.9 \pm 7.9$, p bonf $_{\text {corr }}=1.0, \mathrm{Cl}[-0.054$ to 0.094$]$ ) or the group with the middle discrimination score (i.e., $>0.05 \mu \mathrm{S}$ but $<0.1 \mu \mathrm{S}$, mid blue, $n=42$, mean \pm SD STAl score $38 \pm 10.2$, p ponf_corr $=0.11, \mathrm{Cl}[-0.005$ to 0.145$])$.

\section{Definition of 'non-responders' and numberof participants excluded across studies}

Thirty-two percent (i.e., 16 records) of the records in our systematic literature search included a definition and exclusion of 'non-responders', with percentages of participants excluded as a result of non-responding ranging between $0 \%$ and $14 \%$ (see Figure 6 A). A single study (Chauret et alo, 2014; Oyarzún et al., 2012) reported \% 'non-learners' and \% 'non-responders' as a single value (see Appendix 1-table 2). The definitions differed in: i) the stimulus type(s) used to define 'nonresponding' (CS+ reinforced, CS+ unreinforced, all CS+s, CS-, US), ii) the SCR minimum amplitude criterion used to define a responder (varying between $0.01 \mu \mathrm{S}$ and $0.05 \mu \mathrm{S}$; visual inspection), and iii) the percentage of trials for which these criteria have to be met (see Figure 6B and Appendix 1table 2), as well as a combination thereof.

'Non-responding' was most commonly defined as not showing a sufficient number of responses to the conditioned stimuli (CS+ and CS-), less frequently by the absence of responses to the US or any stimulus (CS+, CS- or US), and in two cases by the absence of responses to the CS+ or context $(C X T+)$ specifically (see Figure 6B). Not surprisingly, the percentage of excluded participants differed substantially depending on the stimulus type used to define 'non-responding' (CS based, 0$10 \%$; CS+/CXT+ based, 10-11\%; US based, 0-4\%; CS and US based, 11-14\%; pre-experimental test based, 5\%; Figure 6A).

Despite these differences in the stimulus types used to define 'non-responding' in the first place, studies differed widely in the amplitude cutoff criterion to be exceeded in order to qualify as a response (see Figure $6 \mathrm{~B}$ ) as well as in the percentage of trials in which this cutoff had to be met (see Appendix 1-table 2).

The question of what (physiological) 'non-responders' during fear acquisition training are and how to identify them might be elucidated by investigating the number of 'non-responses' across trial types (CS and US) across data sets, and whether 'non-responding' to the US predicts 'non-responding' to the CS or vice versa. As expected from Figure 6A, the number of 'non-responses' to the US was low (as was also the case in our data [10\%, Data set 1]), while the number of 'non-responses' to the CS $(48.29 \%)$ was substantially higher - in particular for the CS- $(58.6 \%$; CS+ 'non-responses': $37.9 \%$, see Figure 7 A). This pattern, exemplarily illustrated here in one data set is representative of a larger number of data sets (see Appendix 4, table 1 for details). Furthermore, in our data (Data set 1), all individuals that did not react to the US in more than two thirds of the US trials also showed no responses to the CS ( $n=3$ of $N=119$ ). To summarize, this provides the first evidence that 'non-responding' to the US may predict 'non-responding' to the CS but not vice versa. Furthermore, our data also suggest a positive correlation between the number of 'non-responses' to the US and the number of 'non-responses' to the CS (see Figure 7B for statistics).

\section{Discussion}

In this article, we showed that participant exclusion in fear conditioning research is common (i.e., $40 \%$ of records included) and characterized by substantial operationalizational heterogeneity of definitions for 'non-learners' and (physiological) 'non-responders'. Furthermore, we provide case-examples that illustrate: i) the futility of some definitions of 'non-learners' (i.e., when those classified as 'non-learners' in fact show significant discrimination on both ratings and SCRs as illustrated in Appendix 3 and Appendix 2, respectively) when applied to our data; and ii) the potential sample bias induced by excluding 'non-learners' with respect to individual differences. Furthermore, we provide an overview of SCR 'non-responses' to different stimulus types (CS+, CS- and US) across different data sets (see Appendix 4-tables 1 and 2) as a guide for developing evidence-based criteria 


\section{Box 1. List of reporting details, potential difficulties and recommendations when excluding 'non-learners' (performance-based exclusion) and/or 'non- responders' with a focus on SCRs.}

Please note that this Box can be annotated online.

\section{(A) General reporting details}

\begin{tabular}{ll} 
What to report? & Why is this considered important \\
\hline $\begin{array}{l}\text { Details on data recording and } \\
\text { response quantification pipeline }\end{array}$ & $\begin{array}{l}\text { - because differences in data } \\
\text { recording and quantification (i.e., } \\
\text { response scoring) can make a } \\
\text { substantial difference }\end{array}$
\end{tabular}

to define valid responses Minimal response
define a valid SCR first CS- trial is included or not, and information on trial sequence the earliest at the end of the CS+
- no learning can be evident in the first trial, as the first US may occur at and hence after the scoring window for the CS+-induced SCR

- if the first trial is a CS-, no learning can have taken place as the US has

not been presented yet

- inclusion of the first trial (or the first trials in partial reinforcement protocols) may thus artificially reduce $\mathrm{CS}+/ \mathrm{CS}$ - discrimination

Precise number of trials considered • often difficult/ambiguous to infer (if applicable for each trial type including reinforced and nonreinforced CS+ trials in case of partial reinforcement) this information from the 'Materials and methods' section of a report ${ }^{\mathrm{a}}$

- number of trials that the 'last half' or 'full phase' refers to is contingent on experimental design and hence ambiguous and imprecise (see Figure 2B)

Details of whether results were based on raw or transformed data
- typically, transformations are required to allow interpretation of the reported results and to meet the assumptions of commonly statistical models

\section{What can go wrong or be}

ambiguous?

\section{Recommendations on how to proceed}

- report recording equipment and all settings used (e.g., filter)

- report software used for response quantification

- report precise details of response quantification

- minimally detectable amplitude (e. - test different minimal response g., $0.01,0.02,0.03,0.05 \mu \mathrm{S}$, etc.) may be sample- and equipmentspecific

- no clear recommendations (existing guidelines provide a range of 0.01 to $0.05 \mu \mathrm{S}$ ) because this is influenced by noise level and equipment criteria in the data set and define the cutoff empirically. In our experience (Data set 1), a cutoff was easily determined empirically by visually inspecting responses at different cutoffs (e.g., $<0.01 \mu \mathrm{S}$, between $0.01 \mu \mathrm{S}$ and $0.02 \mu \mathrm{S}$ ) and by evaluating their discrimination from noise

- careful experimental design with respect to trial-sequences (in

in fully randomized partial presentations may cluster in the first particular in partial reinforcement or last half of the acquisition protocols)

training, which will impact on CS+/ - report whether the first trial for CS-discrimination in SCRs both CS+ and CS- is excluded because it may induce noise and bias CS+/CS- discrimination towards non-discrimination and as the first trial is sensitive to trial sequence effects

- precision in reporting rather than relying on the reader making the right inferences

- specify clearly the number of trials per stimulus type that are comprised in the 'last half' or 'full phase'

- provide a justification (theoretical and/or empirical) for this decision ${ }^{b}$

- report details of transformation (e. g., logarithmized [log/LN], rangecorrected, square-root) including the number of trials considered (for each stimulus type) and the sequence of transformations applied and specific formula (e.g. for range-correction) - provide justification for any applied transformation (e.g., violation of assumption of normal distribution of residuals) 
Precise number of excluded participants and specific reasons
- often difficult/ambiguous to infer this information from the

'Materials and methods' section of a report ${ }^{a}$
- different researchers have different opinions on what

exclusion' is (e.g., having individuals discontinue after a first experimental day based on performance should be considered and reported as exclusion)

\section{(B) Specific reporting details for exclusion of 'non-learners'}

\section{What to report?}

\section{$\mathrm{CS}+/ \mathrm{CS}$ - discrimination is}

calculated on the basis of raw SCR or transformed (e.g., logarithmized [log/LN], range-corrected, squareroot) scores

\section{Minimal differential (CS+ vs. CS)} cutoff for 'non-learning' in $\mu \mathrm{S}$

\section{Why is this considered important? ambiguous?}

- the same criteria lead to different proportions of excluded individuals when applying them to raw or transformed data (see Figure 3A and $B$ )

- different cutoffs lead to very different proportions of individuals excluded (see Figure 3 )
What can go wrong or be

\section{Recommendations on how to proceed}

- exact details of transformations (optimally calculation formulas) need to be included for full transparency and reproducibility
- report a breakdown of specific reasons for exclusions with respective $n^{\prime} s$
On what outcome measures is 'non- • 'non-learners' do not necessarily • all outcome measures recorded learning' determined? converge across different outcome need to be reported measures (Appendix 3, Figure 4figure supplement 1)
- exact details on cutoffs need to be included for full transparency and reproducibility

- 'non-learning' should not be based on a single outcome measure or a clear justification needs to be provided as to why a single measure is considered meaningful

\section{If 'non-learning' is determined by - depending on the criteria}

responding during fear acquisition employed, the same individual may training, which trial types and be classified as 'learner' or 'non-

number of trials per trial type were learner' (see Figure 4) considered?

- classification as 'non-learner' should be based on differential scores (CS+ vs. CS-), and the number of trials included for this calculation should be clearly justified. Providing a generally valid recommendation regarding the number of trials to be included is difficult because it critically depends on experimental design choices

If 'non-learning 'criteria are used, do - provide explicit justifications on they differ from criteria that the researcher or the research group used in previous publications? If yes, why were the criteria changed?

Did 'non-learners' really fail to learn? why different criteria were used previously and presently
- report differences between present and previous criteria used including references and justifications
- important as a manipulation check • individuals classified as 'nonbut note that the absence of a statistically significant CS+/CSdiscrimination effect in a group on average cannot be taken to imply that all individuals in this group do not show meaningful CS+/CSdiscrimination learners' may in fact show significant CS+/CS- discrimination significantly in discrimination, and in SCRs (see Appendix 2) or in other do 'non-learners' really not outcome measures (see Figure 3- discriminate in SCRs and other figure supplement 1 and Appendix 4) and hence fail the manipulation check outcome measures? Report the data on this group graphically and/ or statistically in the supplementary material (do not report the full sample with and without exclusions only) 
Are results contingent on the exclusion of 'non-learners'?
- important to allow for transparency and to evaluate the impact of the results
- it is not clearly defined when results differ meaningfully when excluding and including 'nonlearners'
- provide results with and without exclusion of 'non-learners' - additional analyses can be provided as supplementary material. When results are not contingent on the exclusion of 'nonlearners', it is sufficient to mention this briefly in the results of the main manuscript (e.g., results are not contingent on the exclusion of 'nonlearners')

- if the results of the main analyses and hence the main conclusions change when 'non-learners' are excluded, this needs to be included in the main manuscript, and the implications need to be adequately discussed. Please note that this does not necessarily invalidate findings but can refine them

- report sex, age, anxiety levels, awareness 'non-learners'

(C) Specific reporting details for exclusions of 'non-responders'
- important to allow for transparency and evaluation of the potential sample biases introduced

\section{Recommendations on how to} proceed

- exact details of transformations (optimally calculation formulas) need to be included for full transparency and reproducibility

- exact details on cutoffs need to be included for full transparency and reproducibility in $\mu \mathrm{S}$
- the same criteria lead to different proportions of excluded individuals when applying to raw or transformed data (see Figure 3A and $B$ )

- it is often difficult/ambiguous to infer this information from the 'Materials and methods' section of a report ${ }^{a}$

- higher cutoffs could unnecessarily reduce the sample size

Was 'non-responding' determined • determining 'non-responding' in a pre-experimental phase such as during a pre-experimental phase forced-breathing or US calibration? may help to detect malfunctioning of the equipment and allow this to be corrected prior to data acquisition - classification of 'non-responders' independent of the experimental task and its specifications (e.g., number of US presentations)

If 'non-responding' is determined - frequency of 'non-responding' by responding during fear differs substantially between acquisition training, what trial types different stimuli (CS and US) but are considered?
- electrodes may detach between the pre-experimental phase and fear acquisition training (n)
- report details of pre-experimental phase

- classification in SCR 'nonresponders' should be based on a pre-experimental phase if no US presentations occur during the experiment, such as in case of threat of shock experiments, observational conditioning, extinction or return of fear tests

- 'non-responding' to the US may be due to technical failure (i.e., no US was administered)
- classification in SCR 'non-

responders' should not be based on SCRS elicited by CS (CS+, CS- or both), but should be based on US responding

- a question on the estimated number of US presented during fear acquisition training (and all other phases) may serve as a manipulation check

- report sex, age, anxiety levels, awareness 'non-responder'

Descriptive statistics for excluded

a based on our experience with extracting this information from literature identified in the systematic literature search reported in this manuscript.

b 'others have done this previously' is not an acceptable justification in our point of view. 
to define 'non-responders'. Together, we believe that this work contributes to: i) raising awareness of some of the problems associated with performance-based exclusion of participants ('non-learners') and of how this exclusion is implemented, ii) facilitating decision-making on which criteria to employ and not to employ, iii) enhancing transparency and clarity in future publications, and thereby iv) fostering reproducibility and robustness as well as clinical translation in the field of fear conditioning research and beyond.

\section{'Non-learners': conclusions, caveats and considerations}

Operationalizational heterogeneity is illustrated by every single record in our systematic literature search (covering a six months period) that employed definitions of 'non-learners' using a set of idiosyncratic criteria. The true number of definitions in the field applied over decades will be even substantially larger. In the records included here, 6-52\% of participants were excluded (disregarding one study reporting percentages of 'non-learners' and 'non-responders' together with 74\%; cf. Figure 2A), which substantially exceed the percentages recently put forward for 'non-learning' exclusions (Marin et alı, 2019) that were suggested to lie between 4\% (Chauret et al., 2014) and 19\% (Oyarzún et al., 2012).

If several thousand analytical pipelines can be applied, the likelihood of false positives is high (Munafò et al., 2017) and the temptation of their opportunistic (ab)use must be considered a threat. Hence, a constructive discussion on where to go from here and how to not get lost in the garden of forking paths is important. This being said, we do acknowledge that certain research questions or the use of different recording equipment (robust lab equipment vs. novel mobile devices such as smartwatches) may potentially require distinct data-processing pipelines and the exclusion of certain observations (Silberzahn et al., 2018; Simmons et al., 2011), and hence it is not desirable to propose rigid and fixed rules for generic adoption. Procedural differences, in particular the inclusion of outcome measures that require certain triggers to elicit a response (such as startle responses or ratings) have also been shown to impact on the learning process itself (Sjouwerman et al., 2016). Rather, we call for a reconsideration of methods in the field and want to raise awareness to the pitfalls of adopting exclusion criteria from previously published work without critical evaluation of whether these apply meaningfully to one's own research. Furthermore, we want to promote the adoption of transparent reporting of data processing, recording and analyses and strive to suggest standards in the field to reduce heterogeneity based on idiosyncratic customs rather than methodological and theoretical considerations (see Box 1).

Yet, there are many other critical considerations worth discussing beyond the heterogeneous criteria used to define 'non-learners' and their impact on the outcome of statistical tests:

First, 'performance-based exclusion of participants' is often based on a single outcome measure (typically SCRs), despite multiple measures being recorded (for exceptions see Ahmed and Lovibond, 2019; Belleau et al., 2018; Oyarzún et al., 2012). Importantly, 'fear learning' cannot be reliably inferred by means of SCRs, because SCRs capture arousal-related processes and can only be used as a proxy to infer 'fear learning' as fear is closely linked to arousal (Hamm and Weike, 2005). Relatedly, the fact that physiological proxies of 'fear' do not map onto 'fear' itself has been discussed extensively (LeDoux, 2012; LeDoux, 2014).

Second, but related, individuals that fail to show CS+/CS- discrimination in SCRs may show substantial discrimination, as an indicator of successful learning, in other outcome measures such as ratings of fear, US expectancy or fear potentiated startle (Hamm and Weike, 2005; Marin et al., 2019), as illustrated here for fear ratings (see Figure 4-figure supplement 1 and Appendix 3table 1).

Third, a common justification for excluding 'non-learners' is that it is not possible to investigate extinction- or return-of-fear-related phenomena in individuals who 'did not learn'. To our knowledge, there is some evidence (Craske et al., 2008; Plendl and Wotjak, 2010; Prenoveau et al., 2013) that this theoretical assumption does not necessarily hold true, (i.e., CS+/CS- discrimination during fear acquisition training does not necessarily predict CS+/CS- discrimination during other experimental phases) (Gerlicher et al., 2019). An empirical investigation of this, however, would go beyond this manuscript's scope.

Fourth, we provided empirical evidence that those classified as a group of 'non-learners' in SCRs in the literature (sometimes referred to as 'outliers') on the basis of the identified definitions in fact displayed significant CS+/CS- discrimination when applied to our own data. An exception to this 
was using cut offs in differential responding of $<0.05 \mu \mathrm{S}$ (note, however, that a non-significant $\mathrm{CS}+$ / CS- discrimination effect in the group of 'non-learners' as a whole cannot be taken as evidence that all individuals in this group do not in fact display meaningful or statistically significant CS+/CS- discrimination). Hence, in addition to the many conceptual problems we raised here, the operationalization of 'non-learning' in the field failed its critical manipulation check given that those classified as 'non-learners' show clear evidence of learning as a group (i.e., CS+/CS- discrimination, see Appendix 2-table 1).

Fifth, we illustrate a concerning sample bias that is introduced by performance-based participant exclusion. CS+/CS- discrimination in SCRs during fear acquisition training has been linked to a number of individual difference factors (Lonsdorf and Merz, 2017) and, naturally, selecting participants on the basis of SCR CS+/CS- discrimination will also select them on the basis of these individual differences (illustrated by our case example on trait anxiety, Figure 5). In our case example, we illustrate that excluding 'non-learners' biases the sample towards low anxiety scores, which hampers the generalizability and replicability of findings: i) the effect may only exist in low-anxiety individuals but not in the general population, and ii) as fear acquisition is a clinically relevant paradigm, preselection in favor of low-anxiety individuals might represent a threat to the clinical translation of the findings. Many studies in the field of fear conditioning research aim to develop behavioral or pharmacological manipulations to enhance treatment effects or aim to study mechanisms that are relevant for clinical fear and anxiety. Hence, it is highly problematic that these studies may exclude individuals who show response patterns that mimic responses typically observed in anxiety patients when excluding 'non-learners'. In fact, patients suffering from anxiety disorders have been shown to be characterized by generalization of fear from the CS+ to the CS- (Duits et al., 2015).

Sixth, as illustrated by our case example (Figure 3), high CS+/CS- discrimination cutoffs generally favor individuals with high SCR amplitudes despite potentially identical ratios between CS+ and CSamplitudes, which may introduce a sampling bias for individuals characterized by high arousal levels that probably have biological underpinnings. Relatedly, future studies need to empirically address which criteria for SCR transformation and exclusions are more or less sensitive to baseline differences (for an example from startle responding see Bradford et al., 2015; Grillon and Baas, 2002).

In summary, in light of the many (potential) problems associated with performance-based exclusion of participants, we forcefully echo Marin et al.'s conclusion that one needs "to be cautious when excluding SCR non-learners and to consider the potential implications of such exclusion when interpreting the findings from studies of conditioned fear" (Marin et al., 2019, abstract). Routinely, excluding participants who are intentionally or unintentionally characterized by specific individual differences represents a major threat to generalizability, replicability and potentially clinical translation of findings, as results might be contingent on a specific sub-sample and specific sample characteristics. This is also true when researchers are interested in the study of general processes. Furthermore, by excluding these individuals from further analyses, we may miss the opportunity to understand why some individuals do not show discrimination between the CS+ and the CS- in SCRs (or other outcome measures) or whether this lack of discrimination is maintained across subsequent experimental phases. It can be speculated that this lack of discrimination may carry meaningful information - at least for a subsample.

\section{'Non-responders': conclusions, caveats and considerations}

In addition to 'non-learners', 'non-responders' are also often excluded during fear conditioning research. We showed that the definition of 'non-responders', like that of 'non-learners', varies widely across studies. Heterogeneity in definitions manifests in different cutoff criteria for what is considered a valid response, the number of trials and the stimulus type(s) considered (Appendix 1-table 2, Figure 6). Surprisingly, most definitions are based on CS responses (i.e., SCRs to the CS+ and/or CS-) and only few are based on US responses. This highlights a potentially problematic overlap between 'non-learners' and 'non-responders': 'non-responding' to the CS (i.e., CS+ and CS- or CS+ only) is not necessarily indicative of physiological 'non-responding' - especially if high cutoffs are used. In fact, 'non-responding' to the CS may, or at least in some cases, reflect the absence of learning-based patterns in physiological responding - which may carry important information. Having observed the striking differences in percentages of 'non-responses' to the US (10\%) and CS (48\%) observed in our data (see Figure 7 and Appendix 4-table 1), we suggest that physiological 
'non-responding' cannot and should not be determined on the basis of the absence of responding to the CS.

More globally, the group of 'non-responders', as defined by the criteria identified here, probably lumps together several sub-groups: individuals (1) for whom technical problems resulted in no valid SCRs, (2) who fell asleep or did not pay attention, (3) who cognitively learned the CS+/US contingencies but did not express the expected corresponding responses in SCRs, and (4) who were attentive to the experiment but did not learn the contingencies (i.e., unaware participants) and hence did not show the expected SCR patterns (Tabbert et al., 2011).

In summary, although excluding physiological 'non-responders' makes sense (in terms of a manipulation check and independent of the hypothesis), we consider defining 'non-responders' on the basis of the absence of SCRs to the CS as problematic (dependent on the hypothesis). We suggest that physiological SCR 'non-responders' should be defined on the basis of US responses during fear acquisition training or to strong stimuli during pre-conditioning phases such as US calibration, startle habituation or forced breathing (reliably eliciting strong SCRs). If 'non-responding' to the US (during fear acquisition training) is used, it is difficult to suggest a universally valid cutoff with respect to the number or percentage of required valid US responses, because this critically depends on a number of variables such as hardware and sampling rate used. It remains an open question for future work whether data quality of novel mobile devices (e.g., smartwatches) for the acquisition of SCRs differs from traditional, robust lab-based recordings and how this would impact on the frequency of exclusions based on SCRs. Appendix 4 suggests that the cutoff may typically range between $1 / 3$ and 2/3 of valid responses but may be data-set specific. US-based criteria are of course not trivial in multiple-day experiments, in which certain experimental days do not involve the presentation of US or involve few temporally clustered US presentations (i.e., reinstatement), or in paradigms not involving direct exposure to the US (i.e., observational or instructional learning; Haaker et al., 2017). In these cases, the other options listed above are strongly preferred to CS based criteria.

\section{Where do we go from here?}

In this work, we have comprehensively illustrated and argued that most of the current definitions employed to define 'non-learners' and 'non-responders' have to be considered as theoretically and empirically problematic. It is not sufficient, however, to raise awareness to these problems and the practical question of 'Where do we go from here?' remains to be addressed. What can we do to avoid getting lost in the garden of forking paths of exclusion criteria? Here, we would like to offer several solutions to improve practices in the field, which we expect to foster robustness, replicability and potentially clinical translation of findings: (1) transparency in reporting, (2) adopting open science practices, (3) increasing the level and quality of reporting and (4) graphical data presentation, (5) manipulation checks, and (6) fostering critical evaluation. We refer to see Box 1 for specific recommendations.

More precisely, transparency can be enhanced 'if observations are eliminated, authors must also report what the statistical results are if those observations are included', as suggested by Simmons and colleagues, nearly a decade ago (Simmons et al., 2011, Table 2). Here, we echo this call that this recommendation should be implemented routinely in data reporting pipelines when employing performance-based participant exclusions ('non-learners') in fear conditioning research. We also call for a transparent and adequate reporting in the results (in brief) and discussion section rather than providing this information exclusively in the appendix. This being said, it is important to point out that should a finding turn out to be contingent on the exclusion of 'non-learners', this does not necessarily invalidate this finding. On the contrary, it may further specify the finding or hint to possible mechanisms and/or boundary conditions - yet inferences on boundary conditions should be made carefully (Hardwicke and Shanks, 2016). Relatedly, adopting an open science culture will facilitate transparent reporting of exclusion criteria (Nosek et al., 2015) and will minimize the risk of exploiting heterogeneous definitions in the field. Registered reports (Hardwicke and loannidis, 2018), publicly available data including those from excluded participants and pre-registration (Munafò et al., 2017) of definitions and analysis pipelines (loannidis, 2014), as well as openly accessible lab-specific standard operational protocols (SOPs), may also be helpful.

We acknowledge, however, that transparent reporting and particularly pre-registration of exclusion criteria is not trivial in light of the unsatisfactory quality and level of detail in reporting in the field of fear conditioning research. It was striking that the compilation of exclusion criteria ('non- 
learners' and 'non-responders', see Appendix 1-tables 1 and 2) employed in the records included in our systematic literature search required extensive personal exchange with the authors because the definitions provided were often insufficient, ambiguous or incorrect. It is our responsibility as authors, reviewers and editors to improve these reporting standards to an acceptable level. As a guidance, Box 1 provides a compilation of reporting details that we consider important to include in both pre-registered protocols and publications (an editable online version of Box 1 is available to allow for further development, see Box caption).

Our recommendations to improve the level of reporting details and transparency extends to the graphical illustration of results, which should optimally allow for a complete presentation of data (Weissgerber et al., 2015) without risking obscuring important patterns, providing detailed distributional information rather than merely presenting summary statistics (see Weissgerber et al., 2015 for a discussion). Such visualization options include, for instance, scatterplots, box plots, histograms, violin plots as well as their combination (see also Figure 5) in so called 'rain cloud plots' (see Allen et al., 2018 for a tutorial in R, Matlab and Phyton) and utilizing colors or color gradients to visualize different groups of individuals (for instance 'learners' and 'non-learners') or discrimination scores. This will provide readers with the opportunity to evaluate the presented results and conclusions independently and comprehensively.

Finally, if criteria for 'non-learners' or 'non-responders' are employed to exclude participants from data analyses (or continuation of the experiment), we recommend that a sanity or manipulation check should be performed to determine whether - for instance - 'non-learners' really did not learn (i.e., really do not show significant $C S+/ C S$ - discrimination). We have empirically illustrated that most definitions of 'non-learners' fail this manipulation check (Appendix 2-table 1). Yet, it may not be feasible in all cases to determine such statistics, as these may not be appropriate for small samples and correspondingly small sub-groups of 'non-learners'. Relatedly, we urge authors to justify adequately all details of the exclusion criteria (if applied) - both theoretically and practically. Furthermore, we encourage authors, reviewers and editors alike to critically evaluate whether exclusions and applied criteria are warranted in the first place and appropriate in the specific context (vs. mere adopting published or previously employed criteria) and whether these exclusion criteria are transparently reported and discussed if results hinge on them (Steegen et al., 2016).

Furthermore, future work should empirically address the question of how to best define 'nonlearning' in particular in light of different outcome measures in fear conditioning studies, which capture different aspects of defensive responding (Jentsch et al., 2020; Lonsdorf et al., 2017).

\section{Final remarks}

In closing, the field of fear conditioning has been plagued with a lack of consensus on how to define and treat 'non-learners' and 'non-responders', which not seldomly impacts review processes and generates unnecessary lengthy discussions for editors, reviewers and authors. We argue that it is neither ethical (due to an excessive waste of tax money and human resources) nor scientifically meaningful to exclude up to two thirds of a sample. If only one third of the population performs 'as expected' in the experiment, experimental designs, data recording and processing techniques as well as definitions need to be reconsidered. We have shown that findings derived from such highly selective sub-samples may not generalize to other samples or to the general population, and as a consequence might be a threat to clinical translation. Most problematically, however, findings derived from such highly selective samples have been routinely and invariantly generalized to reflect 'general principles' and 'processes' in the past. Not surprisingly, such findings have also suffered replication failures. As such, exclusions of 'non-learners' can in fact be dangerous if not handled transparently (as suggested above), because they may bias and confuse a whole research field and may push research along a misleading path. Thus, we suggest recommendations and consensus suggestions, and recommend that common practices should be critically evaluated before we adopt them in future work, so that the field follows a path towards more robust and replicable research findings. 


\section{Materials and methods}

This project has been pre-registered on the Open Science Framework (OSF) (Lonsdorf et al., 2019, March 22; retrieved from https://osf.io/vjse4).

A systematic literature search was performed according to PRISMA guidelines (Moher et al., 2009) covering all publications (including e-pubs ahead of print) in PubMed during the six months prior to the $22^{\text {nd }}$ March 2019, using the following search terms: threat conditioning OR fear conditioning OR threat acquisition OR fear acquisition OR threat learning OR fear learning OR threat memory OR fear memory OR return of fear OR threat extinction OR fear extinction. In case of author corrections, we included the original study that the correction referred to unless this study itself was already included on the basis of the publication date.

From the identified 854 records listed in PubMed, 152 were included in stage 2 screening (abstract) and 86 were retained for stage 3 screening (full text). Finally, 50 records were included (see Figure 1 for details) that reported results for (1) SCRs as an outcome measure from (2) the fear acquisition training phase (3) in human participants.

\section{Extraction of criteria for 'non-learners' and 'non-responders'}

The 50 records were screened in-depth and information derived from each record was entered into a template file agreed on by the authors prior to literature screening (available from the OSF preregistration https://osf.io/vjse4). We distinguished between 'non-learners' and 'non-responders'. We considered an exclusion to be an exclusion of 'non-learners' if it was based on the key task performance -that is, CS+/CS- discrimination in SCRs. Exclusions were considered as exclusion of 'non-responders' when based on general (physiological) responding (i.e., not based on CS+/CSdiscrimination). Participants who were explicitly excluded because of clear-cut and well-described technical problems, such as abortion of data recording or electrode disattachment, were not included in any definition. Criteria for defining 'non-learners' (see Appendix 1-table 1) and 'nonresponders' (see Appendix 1-table 2) were extracted if applicable for the respective study. In case information in the publication was insufficient or ambiguous, the corresponding authors were contacted and asked for clarification.

\section{Re-analysis of existing data applying the identified exclusion criteria}

One aim of this work was to illustrate empirically the impact of different exclusion criteria on the study outcome and interpretation. To achieve this aim, we initially planned to re-analyze existing data sets and to exclude participants on the basis of the identified definitions, which was expected to demonstrate that results are not robust across the various definitions of 'non-learners' and 'nonresponders' employed. More precisely, we planned to calculate CS+/CS- discrimination across different data sets for all definitions identified by the systematic literature search and to generate corresponding correlation matrices as well as the percentages of zero and non-responses (see preregistration: https://osf.io/vjse4). Because the exclusion criteria identified through the systematic literature search were even more heterogeneous than expected, and as it was difficult to agree on a key outcome to quantify the impact of exclusion criteria, we eventually concluded that such extensive re-analyses would not add much to the tabular and graphical illustration of this heterogeneity. Instead, we provide illustrative case examples for: (i) the proportion of individuals excluded on the basis of the identified exclusion criteria for 'non-learners' (Figure 3) and (ii) the potential sample bias with respect to individual differences (exploratory aim) induced by employing different exclusion criteria features (i.e., discrimination cutoff; Figure 5). As planned, (iii) we provide the percentage of non-responses to the CS+, CS-, CS+ and CS- combined, and the US across different studies, as well as empirical information on the association between CS and US based non-responding as a base to guide empirical recommendations.

Data processing, statistical analyses and figures were generated with R version 3.6 .0 (2019-04-26) using the following packages: cowplot, dplyr, ggplot2 (Wickham, 2009), ggrigdes, car, ez, Isr, psychReport, lubridate, RColorBrewer and flipPlot packages. Sanky plots were generated with help of https://app.displayr.com. 


\section{Data sets}

\section{Data set 1}

Data set 1 is part of the baseline measurement of an ongoing longitudinal fear conditioning study. Here, fear ratings and SCR data from the first test-timepoint $\left(T_{0}\right)$ were included $(N=119,79$ females, mean \pm SD age of $25 \pm 4$ years) whereas $\mathrm{fMRI}$ data were not used. All participants gave written informed consent to the protocol which was approved by the local ethics committee (PV 5157, Ethics Committee of the General Medical Council Hamburg).

Data set 1 is employed to illustrate a case example for the proportion of participants excluded when employing different CS+/CS- discrimination cutoffs ('non-learners', Figure 3) as well as the number of zero-responses across different stimulus types ('non-responders') and their association (Figure 7). Furthermore, we aimed to test exploratively whether even in groups defined as 'nonlearners' a significant CS+/CS- discrimination on SCR and fear ratings can be detected (all results presented in the Appendix are based on Data set 1).

\section{Paradigm and stimuli}

The two-day paradigm consisted of habituation and acquisition training (day 1) and extinction training and recall testing (day 2) without any contingency instructions provided. Here, only data from the acquisition training phase (100\% reinforcement rate) were used. CS were two light grey fractals, presented 14 times each in a pseudo-randomized order for 6-8 s (mean: $7 \mathrm{~s}$ ). Visual stimuli were identical for all participants, but allocation to CS+ and CS- was counterbalanced between participants. During inter-trial intervals (ITIs), a white fixation cross was shown for 10-16 s (mean: $13 \mathrm{~s}$ ). All stimuli were presented on a light gray background and controlled by Presentation software (Version 14.8, Neurobehavioral Systems, Inc, Albany California, USA).

The electrotactile stimulus, serving as US, consisted of three $10 \mathrm{~ms}$ electrotactile rectangular pulses with an interpulse interval of 50 ms (onset: 200 ms before CS+ offset) and was administered to the back of the right hand of the participants. It was generated by a Digitimer DS7A constant current stimulator (Welwyn Garden City, Hertfordshire, UK) and delivered through a $1 \mathrm{~cm}$ diameter platinum pin surface electrode (Speciality Developments, Bexley, UK). The electrode was attached between the metacarpal bones of the index and middle finger. US intensity was individually calibrated in a standardized step-wise procedure aiming at an unpleasant, but still tolerable level.

\section{SCRS}

SCRs were semi-manually scored by using a custom-made computer program (EDA View) as the first response from trough to peak 0.9-3.5 s after CS onset (0.9-2.5 s after US onset) as recommended (Boucsein et al., 2012; Sjouwerman and Lonsdorf, 2019). The maximum rise time was set to $5 \mathrm{~s}$. Data were down-sampled to $10 \mathrm{~Hz}$. Each scored SCR was checked visually, and the scoring suggested by EDA View was corrected if necessary (e.g., the foot or trough was misclassified by the algorithm). Data with recording artifacts or excessive baseline activity (i.e., more than half of the response amplitudes) were treated as missing data points and excluded from the analyses. SCRs below $0.01 \mu \mathrm{S}$ or the absence of any SCR within the defined time window were classified as nonresponses and set to 0 . The threshold of $0.01 \mu \mathrm{S}$ for this data set was determined empirically by visually inspecting response specifically above and below this cutoff, which suggested that in this data set, responses $>0.01 \mu \mathrm{S}$ can be reliably identified. 'Non-responders' $(\mathrm{N}=3)$ were defined as individuals who showed more than two thirds of non-responses to the US (10 or more non-responses out of 14 US trials, see Appendix 4-table 2). Three individuals were classified as 'non-responders' and these individuals did not show any responses to the CS either. The three participants classified as 'non-responders' (see above) were only excluded for the analyses of 'non-learners'. Raw SCR amplitudes were normalized by taking the natural logarithm and range-corrected by dividing each logarithmized SCR by the maximum amplitude (maximum SCR to a CS or a US) per participant and day.

\section{Fear ratings}

Fear ratings were provided by participants through ratings on a visual analog scale (VAS) on the screen asking 'how much stress, fear, and tension' they experienced when they last saw the CS+ and CS-. The fear ratings used for the purpose of this manuscript are those obtained after fear acquisition training (no ratings were acquired during this phase). Answers were given within $5 \mathrm{~s}$ on the VAS, 
which ranged from 0 (answer = none) to 25 (answer = maximum) by using a button box. Pressing the buttons moved a bar on the VAS to the aimed value and answers were logged in by pressing another button. Non-registered ratings were considered as missing values (8.4\%).

\section{Statistical analysis}

To test whether exclusion groups differ in CS+/CS- discrimination, a mixed ANOVA with CS+/CSdiscrimination in SCR or fear ratings as the dependent variable and the between-subjects factor 'Exclusion group' and the within-subject factor 'CS-type' was performed. Note that it is circular to test for differences in SCR CS+/CS- discrimination between groups that were selected on the basis of different SCR CS+/CS- discrimination cutoffs in the first place. Still, it is relevant to test whether all groups classified as 'non-learners' in the literature do indeed fail to show evidence of learning, which would be indicated by a lack of significant CS+/CS- discrimination in SCRs in this case. In essence, this is a test to evaluate whether the exclusion criteria used in the literature do indeed achieve what they purport to do, that is, classify a group of participants that do not show evidence of learning. To test whether these exclusion groups discriminated in SCRs and fear ratings, exclusion groups were cumulated, and $t$-tests were performed for each cumulative group (see Appendices 2 and 3, respectively). We acknowledge, however, that the absence of a statistically significant CS+/ CS- discrimination effect in a group on average cannot be taken to imply that all individuals in this group do not show meaningful CS+/CS- discrimination. As such, this is a rather conservative test. To correct for multiple testing, all $p$-values deriving from $t$-tests were adjusted using the Bonferroni procedure. As effect size, Cohen's $d$ was reported for $t$-tests and partial eta-squared for ANOVAs. To illustrate the association between the non-responses to the US and the non-responses to the CS, a Spearman rank correlation test was computed.

\section{Data set 2}

For the purpose of this manuscript, a final sample of 268 individuals (195 female, mean \pm SD age of $25 \pm 4$ years) was re-analyzed. This sample is reported in a recent pre-print (Sjouwerman et al., 2018) in which we observed an association between trait anxiety and CS+/CS- discrimination in SCRs. Here, the re-analysis and graphical illustration of these data serve the purpose of a case example to illustrate the potential sample bias that may be induced by employing performance-based exclusion (Figure 5).

\section{Paradigm and stimuli}

A detailed experimental description is included in the preprint Sjouwerman et al. (2018). In brief, participants underwent a $100 \%$ reinforcement fear acquisition training phase in a behavioral laboratory setting, including $9 \mathrm{CS}+$ and $9 \mathrm{CS}$ - trials, presented for $6 \mathrm{~s}$ each. Consequently, 9 US presentations were included that coincided $100 \mathrm{~ms}$ prior to CS+ offset. Trials were interleaved by 10-13 s ITls with a white fixation cross presented on a black background. Black geometrical shapes served as CS, and electrical stimulation delivered by a DS7A electrical stimulator (Digitimer, Welwyn Garden City, UK) onto the outer surface of the right hand served as US. The intensity of the US was individually calibrated with a stair-case procedure in order to reach an unpleasant but tolerable level. Not of interest to the current case example were the acoustic startle probes (95 dB(A) burst of white noise) presented to elicit a startle response in two thirds of all acquisition trials, as well as three fear-rating blocks probed intermittently during fear acquisition training. Startle probes were presented 4 or $5 \mathrm{~s}$ post-CS onset, and 5 or $7 \mathrm{~s}$ post-ITI onset. No contingency instructions were given.

SCRs

SCRs were quantified as the first SCR within 0.9-4.0 s after stimulus onset (CS or US) and were scored semi-manually from trough-to-peak using a custom-made program. Signal increases smaller than $0.02 \mu \mathrm{S}$ were treated as non-responses, that is set to 0 . (Please note that this cut-off was not empirically determined as in Data set 1 but adopted from the previous publication of Data set 2 . As we present re-analyses here, we decided not to change the cut-off to maintain comparability.) Responses confounded by recording artifacts, such as responses moving beyond the sampling window, excessive baseline activity, or electrode detachment were treated as missing values. Raw response amplitudes per trial were log-transformed and range-corrected for the maximum CS or US response per participant. Individuals not showing any valid SCR (i.e., missing or zero responses) in 
more or equal than two thirds ( $\geq 6$ out of 9, see Appendix 4-table 2) of US trials were treated as physiological 'non-responders' $(n=19)$ and were consequently excluded from graphical illustration and the statistical analysis. In addition, 31 participants were excluded prior to physiological processing, either because of abortion of the experiment or due to technical failures during data acquisition (e.g. errors during saving, overwritten logfile, or missing markers), leaving 307 out of 357 individuals with valid SCR data for fear acquisition training. Of these 307 participants, 39 had incomplete STAI-T data (Spielberger et al., 1983) resulting in a final sample size for this case example of 268 individuals (195 female, mean \pm SD age of $25 \pm 4$ years).

\section{Statistical analysis}

To test whether different exclusion groups differ in their mean trait anxiety levels, a univariate ANOVA with STAI-T score as the dependent variable and exclusion group as the independent variable was carried out. Post hoc pairwise t-tests were conducted to compare trait anxiety scores between the different exclusion group levels. The post hoc tests were corrected for multiple testing, using the Bonferroni correction method. 95\% family wise confidence levels were determined using TukeyHSD tests.

\section{Acknowledgements}

The project is part of a European wide network (EIFEL-ROF network) of researchers working on meta-research topics in the field of fear conditioning research, which is funded by the German Research foundation (DFG; Grant ID LO1980/2-1) to TBL and CJM. Data used for re-analyses in the main manuscript paper are derived from projects funded by the DFG to TBL (Data set 1: Collaborative Research Center project number 44541416 TRR 58, sub-project B07. Data set 2: LO 1980/1-1). Data reported in Appendix 1-table 1 are also funded by the German Research Foundation to CJM (Collaborative Research Center SFB 1280 project number 316803389, sub-project A09) and JW (WE 5873/1-1 and WE 2762/5-1). The authors represent eight different research groups across three European countries (Germany, the Netherlands, and Belgium).

We thank Prof. Dr. Matthias Gamer, University of Würzburg, for providing EDA View for SCR response quantification.

The authors thank Manuel Kuhn, Jan Haaker, Tanja Jovanovic and Dean Mobbs for helpful suggestions during discussions on this project. We also thank Jan Haaker for help with initial literature screening.

\section{Additional information}

Funding

\begin{tabular}{lll} 
Funder & Grant reference number & Author \\
\hline $\begin{array}{l}\text { Deutsche Forschungsge- } \\
\text { meinschaft }\end{array}$ & LO 1980/2-1 & $\begin{array}{l}\text { Tina B Lonsdorf } \\
\text { Christian J Merz }\end{array}$ \\
\hline $\begin{array}{l}\text { Deutsche Forschungsge- } \\
\text { meinschaft }\end{array}$ & LO 1980/1-1 & Tina B Lonsdorf \\
\hline $\begin{array}{l}\text { Deutsche Forschungsge- } \\
\text { meinschaft }\end{array}$ & Project B07 44541416 & Tina B Lonsdorf \\
\hline $\begin{array}{l}\text { Deutsche Forschungsge- } \\
\text { meinschaft }\end{array}$ & $316803389-$ SFB1280 & Christian J Merz \\
\hline $\begin{array}{l}\text { Deutsche Forschungsge- } \\
\text { meinschaft }\end{array}$ & WE 5873/1-1 & Julia Wendt \\
$\begin{array}{l}\text { Deutsche Forschungsge- } \\
\text { meinschaft }\end{array}$ & WE 5873/5-1 & Julia Wendt \\
\hline
\end{tabular}

The funders had no role in study design, data collection and interpretation, or the decision to submit the work for publication. 
Author contributions

Tina B Lonsdorf, Conceptualization, Data curation, Formal analysis, Supervision, Funding acquisition, Visualization, Methodology, Writing - original draft, Project administration, Writing - review and editing, Concieved the study, Organized the project group, Contributed to data acquisition, Data analysis (systematic literature search, Dataset 1, Dataset 2, Data visualization, Drafting the manuscript, Revised the draft critically and approved the final version to be published; Maren Klingelhöfer-Jens, Data curation, Formal analysis, Visualization, Writing - original draft, Writing - review and editing, Contributed to data analysis and data visualization (data set 1), Drafting the manuscript, Revised the draft critically and approved the final version to be published; Marta Andreatta, Tom Beckers, Anastasia Chalkia, Anna Gerlicher, Valerie L Jentsch, Shira Meir Drexler, Gaetan Mertens, Jan Richter, Julia Wendt, Formal analysis, Writing - original draft, Writing - review and editing, Contributed to data acquisition and data analysis (systematic literature search), Drafting the manuscript, Revised the draft critically and approved the final version to be published; Rachel Sjouwerman, Data curation, Formal analysis, Visualization, Writing - original draft, Writing - review and editing, Contributed to data acquisition, Data analysis (dataset 2), Data visualization, Drafting the manuscript, Revised the draft critically and approved the final version to be published; Christian J Merz, Conceptualization, Formal analysis, Supervision, Funding acquisition, Writing - original draft, Writing - review and editing, Conceived the study, Contributed to data acquisition and data analysis (systematic literature search), Drafting the manuscript, Revised the draft critically and approved the final version to be published

\section{Author ORCIDs}

Tina B Lonsdorf (iD) https://orcid.org/0000-0003-1501-4846

Marta Andreatta (iD https://orcid.org/0000-0002-1217-8266

Tom Beckers (D) https://orcid.org/0000-0002-9581-1505

Anastasia Chalkia (D) https://orcid.org/0000-0002-1613-2281

Valerie L Jentsch (DiD https://orcid.org/0000-0001-9318-9540

Shira Meir Drexler (iD https://orcid.org/0000-0001-8797-6900

Jan Richter (iD https://orcid.org/0000-0002-7127-6990

Julia Wendt (D) https://orcid.org/0000-0003-2299-5881

Christian J Merz (D) https://orcid.org/0000-0001-5679-6595

Ethics

Human subjects: Study 1: All participants gave written informed consent to the protocol which was approved by the local ethics committee (PV 5157, Ethics Committee of the General Medical Council Hamburg). Study 2: All participants gave written informed consent to the protocol which was approved by the Ethical Review Board of the German Psychological Association (TL072015).

Decision letter and Author response

Decision letter https://doi.org/10.7554/eLife.52465.sa1

Author response https://doi.org/10.7554/eLife.52465.sa2

\section{Additional files}

Supplementary files

- Transparent reporting form

Data availability

The minimal data sets (data set 1 and data set 2, both represent re-analysis of existing data), which were analysed during the current study, as well as code for figure production are are available at OSF under https://osf.io/mkxqe/ and DOI: https://doi.org/10.17605/OSF.IO/MKXOE.

The following datasets were generated: 


\begin{tabular}{lllll}
\hline Author(s) & Year & Dataset title & Dataset URL & $\begin{array}{l}\text { Database and } \\
\text { Identifier }\end{array}$ \\
\hline $\begin{array}{l}\text { Tina B Lonsdorf, } \\
\text { Maren Klingelhöfer- } \\
\text { Jens }\end{array}$ & 2019 & Data_and_code_dataset1 & https://osf.io/w9y8z/ & $\begin{array}{l}\text { Open Science } \\
\text { Framework, w9y8z }\end{array}$ \\
$\begin{array}{l}\text { Tina B Lonsdorf, } \\
\text { Rachel Sjouwerman }\end{array}$ & 2019 & Data_and_code_dataset2 & https://osf.io/7c5ag/ & Open Science \\
& & & Framework, 7c5ag \\
\hline
\end{tabular}

\section{References}

Ahmed O, Lovibond PF. 2019. Rule-based processes in generalisation and peak shift in human fear conditioning. Quarterly Journal of Experimental Psychology 72:118-131. DOI: https://doi.org/10.1177/1747021818766461

Alexandra Kredlow M, Pineles SL, Inslicht SS, Marin MF, Milad MR, Otto MW, Orr SP. 2017. Assessment of skin conductance in african american and Non-African american participants in studies of conditioned fear.

Psychophysiology 54:1741-1754. DOI: https://doi.org/10.1111/psyp.12909, PMID: 28675471

Allen M, Poggiali D, Whitaker K, Marshall TR, Kievit R. 2018. Raincloud plots: a multi-platform tool for robust data visualization. PeerJ 4:63. DOI: https://doi.org/10.7287/peerj.preprints.27137v1

Baeuchl C, Hoppstädter M, Meyer P, Flor H. 2019. Contingency awareness as a prerequisite for differential contextual fear conditioning. Cognitive, Affective, \& Behavioral Neuroscience 19:811-828. DOI: https://doi. org/10.3758/s13415-018-00666-z

Belleau EL, Pedersen WS, Miskovich TA, Helmstetter FJ, Larson CL. 2018. Cortico-limbic connectivity changes following fear extinction and relationships with trait anxiety. Social Cognitive and Affective Neuroscience 13 1037-1046. DOI: https://doi.org/10.1093/scan/nsy073, PMID: 30137604

Boucsein W, Fowles DC, Grimnes S, Ben-Shakhar G, roth WT, Dawson ME, Filion DL, Society for Psychophysiological Research Ad Hoc Committee on Electrodermal Measures. 2012. Publication recommendations for electrodermal measurements. Psychophysiology 49:1017-1034. DOI: https://doi.org/10. 1111/j.1469-8986.2012.01384.x, PMID: 22680988

Bradford DE, Starr MJ, Shackman AJ, Curtin JJ. 2015. Empirically based comparisons of the reliability and validity of common quantification approaches for eyeblink startle potentiation in humans. Psychophysiology $\mathbf{5 2}$ : 1669-1681. DOI: https://doi.org/10.1111/psyp.12545

Chauret M, La Buissonnière-Ariza V, Lamoureux Tremblay V, Suffren S, Servonnet A, Pine DS, Maheu FS. 2014. The conditioning and extinction of fear in youths: what's sex got to do with it? Biological Psychology 100:97105. DOI: https://doi.org/10.1016/j.biopsycho.2014.06.001, PMID: 24929048

Craske MG, Kircanski K, Zelikowsky M, Mystkowski J, Chowdhury N, Baker A. 2008. Optimizing inhibitory learning during exposure therapy. Behaviour Research and Therapy 46:5-27. DOI: https://doi.org/10.1016/j. brat.2007.10.003

Drexler SM, Merz CJ, Hamacher-Dang TC, Tegenthoff M, Wolf OT. 2015. Effects of cortisol on reconsolidation of reactivated fear memories. Neuropsychopharmacology 40:3036-3043. DOI: https://doi.org/10.1038/npp. 2015.160, PMID: 26058664

Drexler SM, Merz CJ, Wolf OT. 2018. Preextinction stress prevents Context-Related renewal of fear. Behavior Therapy 49:1008-1019. DOI: https://doi.org/10.1016/j.beth.2018.03.001, PMID: 30316481

Duits P, Cath DC, Lissek S, Hox JJ, Hamm AO, Engelhard IM, van den Hout MA, Baas JMP. 2015. Updated meta-analysis of classical fear conditioning in the anxiety disorders. Depression and Anxiety 32:239-253. DOI: https://doi.org/10.1002/da.22353

Flake JK, Fried E. 2019. Measurement schmeasurement: questionable measurement practices and how to avoid them. PsyArXiv. DOI: https://doi.org/10.31234/osf.io/hs7wm

Garpenstrand H, Annas P, Ekblom J, Oreland L, Fredrikson M. 2001. Human fear conditioning is related to dopaminergic and serotonergic biological markers. Behavioral Neuroscience 115:358-364. DOI: https://doi. org/10.1037/0735-7044.115.2.358, PMID: 11345960

Gelman A, Loken E. 2013. The Garden of Forking Paths: Why Multiple Comparisons Can Be a Problem, Even When There Is No "Fishing Expedition " or "P-Hacking " and the Research Hypothesis Was Posited Ahead of Time: Columbia Statistics. http://www.stat.columbia.edu/ gelman/research/unpublished/p_hacking.pdf.

Gerlicher AMV, Tüscher O, Kalisch R. 2018. Dopamine-dependent prefrontal reactivations explain long-term benefit of fear extinction. Nature Communications 9:1-9. DOI: https://doi.org/10.1038/s41467-018-06785-y

Gerlicher AMV, Tüscher O, Kalisch R. 2019. L-DOPA improves extinction memory retrieval after successful fear extinction. Psychopharmacology 236:3401-3412. DOl: https://doi.org/10.1007/s00213-019-05301-4, PMID: 31243481

Grégoire L, Greening SG. 2019. Opening the reconsolidation window using the mind's eye: Extinction training during reconsolidation disrupts fear memory expression following mental imagery reactivation. Cognition 183: 277-281. DOI: https://doi.org/10.1016/j.cognition.2018.12.001

Grillon C, Baas JM. 2002. Comments on the use of the startle reflex in psychopharmacological challenges: impact of baseline startle on measurement of fear-potentiated startle. Psychopharmacology 164:236-238. DOI: https://doi.org/10.1007/s00213-002-1164-5, PMID: 12481758 
Gruss LF, Keil A. 2019. Sympathetic responding to unconditioned stimuli predicts subsequent threat expectancy, orienting, and visuocortical Bias in human aversive pavlovian conditioning. Biological Psychology 140:64-74. DOI: https://doi.org/10.1016/j.biopsycho.2018.11.009, PMID: 30476520

Haaker J, Golkar A, Selbing I, Olsson A. 2017. Assessment of social transmission of threats in humans using observational fear conditioning. Nature Protocols 12:1378-1386. DOI: https://doi.org/10.1038/nprot.2017.027, PMID: 28617449

Hamacher-Dang TC, Merz CJ, Wolf OT. 2015. Stress following extinction learning leads to a context-dependent return of fear. Psychophysiology 52:489-498. DOI: https://doi.org/10.1111/psyp.12384, PMID: 25410416

Hamm AO, Greenwald MK, Bradley MM, Lang PJ. 1993. Emotional learning, hedonic change, and the startle probe. Journal of Abnormal Psychology 102:453-465. DOI: https://doi.org/10.1037/0021-843X.102.3.453, PMID: 8408958

Hamm AO, Weike Al. 2005. The neuropsychology of fear learning and fear regulation. International Journal of Psychophysiology 57:5-14. DOI: https://doi.org/10.1016/j.ijpsycho.2005.01.006

Hardwicke TE, loannidis JPA. 2018. Mapping the universe of registered reports. Nature Human Behaviour 2: 793-796. DOI: https://doi.org/10.1038/s41562-018-0444-y, PMID: 31558810

Hardwicke TE, Shanks DR. 2016. Reply to walker and Stickgold: proposed boundary conditions on memory reconsolidation will require empirical verification. PNAS 113:E3993-E3994. DOI: https://doi.org/10.1073/pnas. 1608235113

Hartley CA, Coelho CAO, Boeke E, Ramirez F, Phelps EA. 2019. Individual differences in blink rate modulate the effect of instrumental control on subsequent pavlovian responding. Psychopharmacology 236:87-97. DOI: https://doi.org/10.1007/s00213-018-5082-6, PMID: 30386862

Head ML, Holman L, Lanfear R, Kahn AT, Jennions MD. 2015. The extent and consequences of p-hacking in science. PLOS Biology 13:e1002106. DOI: https://doi.org/10.1371/journal.pbio.1002106, PMID: 25768323

Hermann A, Stark R, Milad MR, Merz CJ. 2016. Renewal of conditioned fear in a novel context is associated with hippocampal activation and connectivity. Social Cognitive and Affective Neuroscience 11:1411-1421. DOI: https://doi.org/10.1093/scan/nsw047, PMID: 27053767

Hu J, Wang W, Homan P, Wang P, Zheng X, Schiller D. 2018. Reminder duration determines threat memory modification in humans. Scientific Reports 8:8848. DOI: https://doi.org/10.1038/s41598-018-27252-0, PMID: 2 9891856

Hu J, Wang Z, Feng X, Long C, Schiller D. 2019. Post-retrieval oxytocin facilitates next day extinction of threat memory in humans. Psychopharmacology 236:293-301. DOI: https://doi.org/10.1007/s00213-018-5074-6, PMID: 30370450

loannidis JP. 2014. How to make more published research true. PLOS Medicine 11:e1001747. DOI: https://doi. org/10.1371/journal.pmed.1001747, PMID: 25334033

Jentsch VL, Wolf OT, Merz CJ. 2020. Temporal dynamics of conditioned skin conductance and pupillary responses during fear acquisition and extinction. International Journal of Psychophysiology 147:93-99. DOI: https://doi.org/10.1016/j.ijpsycho.2019.11.006

John LK, Loewenstein G, Prelec D. 2012. Measuring the prevalence of questionable research practices with incentives for truth telling. Psychological Science 23:524-532. DOI: https://doi.org/10.1177/ 0956797611430953, PMID: 22508865

LeDoux J. 2012. Rethinking the emotional brain. Neuron 73:653-676. DOI: https://doi.org/10.1016/j.neuron. 2012.02.004, PMID: 22365542

LeDoux JE. 2014. Coming to terms with fear. PNAS 111:2871-2878. DOI: https://doi.org/10.1073/pnas. 1400335111

Leuchs L, Schneider M, Spoormaker VI. 2019. Measuring the conditioned response: a comparison of pupillometry, skin conductance, and startle electromyography. Psychophysiology 56:e13283. DOI: https://doi. org/10.1111/psyp.13283, PMID: 30259985

Lonsdorf TB, Menz MM, Andreatta M, Fullana MA, Golkar A, Haaker J, Heitland I, Hermann A, Kuhn M, Kruse O, Meir Drexler S, Meulders A, Nees F, Pittig A, Richter J, Römer S, Shiban Y, Schmitz A, Straube B, Vervliet B, et al. 2017. Don't fear 'fear conditioning': Methodological considerations for the design and analysis of studies on human fear acquisition, extinction, and return of fear. Neuroscience \& Biobehavioral Reviews 77:247-285. DOI: https://doi.org/10.1016/j.neubiorev.2017.02.026, PMID: 28263758

Lonsdorf TB, Merz CJ, Fullana MA. 2019. Fear extinction retention: is it what we think it is? Biological Psychiatry 85:1074-1082. DOI: https://doi.org/10.1016/j.biopsych.2019.02.011, PMID: 31005240

Lonsdorf TB, Merz CJ. 2017. More than just noise: inter-individual differences in fear acquisition, extinction and return of fear in humans - Biological, experiential, temperamental factors, and methodological pitfalls. Neuroscience \& Biobehavioral Reviews 80:703-728. DOI: https://doi.org/10.1016/j.neubiorev.2017.07.007

Marin MF, Barbey F, Rosenbaum BL, Hammoud MZ, Orr SP, Milad MR. 2019. Absence of conditioned responding in humans: a bad measure or individual differences? Psychophysiology 57:e13350. DOI: https://doi. org/10.1111/psyp.13350, PMID: 30758048

Meir Drexler S, Merz CJ, Hamacher-Dang TC, Wolf OT. 2016. Cortisol effects on fear memory reconsolidation in women. Psychopharmacology 233:2687-2697. DOI: https://doi.org/10.1007/s00213-016-4314-x, PMID: 271371 98

Meir Drexler S, Merz CJ, Lissek S, Tegenthoff M, Wolf OT. 2019. Reactivation of the unconditioned stimulus inhibits the return of fear independent of cortisol. Frontiers in Behavioral Neuroscience 13:254. DOI: https:// doi.org/10.3389/fnbeh.2019.00254, PMID: 31780910 
Meir Drexler S, Wolf OT. 2017. Stress disrupts the reconsolidation of fear memories in men.

Psychoneuroendocrinology 77:95-104. DOI: https://doi.org/10.1016/j.psyneuen.2016.11.027, PMID: 28024275

Mertens G, Leer A, van Dis EAM, Vermeer L, Steenhuizen A, van der Veen L, Engelhard IM. 2019. Secondary extinction reduces reinstatement of threat expectancy and conditioned skin conductance responses in human fear conditioning. Journal of Behavior Therapy and Experimental Psychiatry 62:103-111. DOI: https://doi.org/ 10.1016/j.jbtep.2018.09.007, PMID: 30296630

Merz CJ, Hamacher-Dang TC, Wolf OT. 2014. Exposure to stress attenuates fear retrieval in healthy men. Psychoneuroendocrinology 41:89-96. DOI: https://doi.org/10.1016/j.psyneuen.2013.12.009, PMID: 24495610

Merz CJ, Hamacher-Dang TC, Stark R, Wolf OT, Hermann A. 2018a. Neural underpinnings of cortisol effects on fear extinction. Neuropsychopharmacology 43:384-392. DOI: https://doi.org/10.1038/npp.2017.227, PMID: 2 8948980

Merz CJ, Kinner VL, Wolf OT. 2018b. Let's talk about sex ... differences in human fear conditioning. Current Opinion in Behavioral Sciences 23:7-12. DOI: https://doi.org/10.1016/j.cobeha.2018.01.021

Moher D, Liberati A, Tetzlaff J, Altman DG, PRISMA Group. 2009. Preferred reporting items for systematic reviews and meta-analyses: the PRISMA statement. PLOS Medicine 6:e1000097. DOI: https://doi.org/10.1371/ journal.pmed.1000097, PMID: 19621072

Morriss J, Chapman C, Tomlinson S, van Reekum CM. 2018. Escape the bear and fall to the lion: the impact of avoidance availability on threat acquisition and extinction. Biological Psychology 138:73-80. DOI: https://doi. org/10.1016/j.biopsycho.2018.08.017, PMID: 30144498

Morriss J, van Reekum CM. 2019. I feel safe when i know: contingency instruction promotes threat extinction in high intolerance of uncertainty individuals. Behaviour Research and Therapy 116:111-118. DOI: https://doi.org/ 10.1016/j.brat.2019.03.004, PMID: 30878772

Munafò MR, Nosek BA, Bishop DVM, Button KS, Chambers CD, Percie du Sert N, Simonsohn U, Wagenmakers E-J, Ware JJ, loannidis JPA. 2017. A manifesto for reproducible science. Nature Human Behaviour 1:0021. DOI: https://doi.org/10.1038/s41562-016-0021

Naveteur J, Freixa I Baque E. 1987. Individual differences in electrodermal activity as a function of subjects' anxiety. Personality and Individual Differences 8:615-626. DOI: https://doi.org/10.1016/0191-8869(87)90059-6

Nitta Y, Takahashi T, Haitani T, Sugimori E, Kumano H. 2018. Avoidance behavior prevents modification of fear memory during reconsolidation. Psychological Reports 15:33294118811116. DOI: https://doi.org/10.1177/ 0033294118811116

Nosek BA, Alter G, Banks GC, Borsboom D, Bowman SD, Breckler SJ, Buck S, Chambers CD, Chin G, Christensen G, Contestabile M, Dafoe A, Eich E, Freese J, Glennerster R, Goroff D, Green DP, Hesse B, Humphreys $M$, Ishiyama J, et al. 2015. Promoting an open research culture. Science 348:1422-1425. DOI: https://doi.org/10.1126/science.aab2374

Oyarzún JP, Lopez-Barroso D, Fuentemilla L, Cucurell D, Pedraza C, Rodriguez-Fornells A, de Diego-Balaguer R. 2012. Updating fearful memories with extinction training during reconsolidation: a human study using auditory aversive stimuli. PLOS ONE 7:e38849. DOI: https://doi.org/10.1371/journal.pone.0038849, PMID: 22768048

Oyarzún JP, Càmara E, Kouider S, Fuentemilla L, de Diego-Balaguer R. 2019. Implicit but not explicit extinction to threat-conditioned stimulus prevents spontaneous recovery of threat-potentiated startle responses in humans. Brain and Behavior 9:e01157. DOI: https://doi.org/10.1002/brb3.1157, PMID: 30516021

Pavlov I. 1927. Conditioned Reflexes. Oxford University Press.

Plendl W, Wotjak CT. 2010. Dissociation of within- and between-session extinction of conditioned fear. Journal of Neuroscience 30:4990-4998. DOI: https://doi.org/10.1523/JNEUROSCI.6038-09.2010, PMID: 20371819

Prenoveau JM, Craske MG, Liao B, Ornitz EM. 2013. Human fear conditioning and extinction: timing is everything. ..or is it? Biological Psychology 92:59-68. DOI: https://doi.org/10.1016/j.biopsycho.2012.02.005, PMID: 22349998

Reddan MC, Wager TD, Schiller D. 2018. Attenuating neural threat expression with imagination. Neuron 100: 994-1005. DOI: https://doi.org/10.1016/j.neuron.2018.10.047, PMID: 30465766

Schiller D, Monfils MH, Raio CM, Johnson DC, Ledoux JE, Phelps EA. 2010. Preventing the return of fear in humans using reconsolidation update mechanisms. Nature 463:49-53. DOI: https://doi.org/10.1038/ nature08637, PMID: 20010606

Schiller D, Monfils MH, Raio CM, Johnson DC, LeDoux JE, Phelps EA. 2018. Addendum: preventing the return of fear in humans using reconsolidation update mechanisms. Nature 562:E21. DOI: https://doi.org/10.1038/ s41586-018-0405-7, PMID: 30050064

Silberzahn R, Uhlmann EL, Martin DP, Anselmi P, Aust F, Awtrey E, Bahník Š, Bai F, Bannard C, Bonnier E, Carlsson R, Cheung F, Christensen G, Clay R, Craig MA, Dalla Rosa A, Dam L, Evans MH, Flores Cervantes I, Fong N, et al. 2018. Many analysts, one data set: making transparent how variations in analytic choices affect results. Advances in Methods and Practices in Psychological Science 1:337-356. DOI: https://doi.org/10.1177/ 2515245917747646

Simmons JP, Nelson LD, Simonsohn U. 2011. False-positive psychology: undisclosed flexibility in data collection and analysis allows presenting anything as significant. Psychological Science 22:1359-1366. DOI: https://doi. org/10.1177/0956797611417632, PMID: 22006061

Sjouwerman R, Niehaus J, Kuhn M, Lonsdorf TB. 2016. Don't startle me-Interference of startle probe presentations and intermittent ratings with fear acquisition. Psychophysiology 53:1889-1899. DOI: https://doi. org/10.1111/psyp.12761, PMID: 27628268 
Sjouwerman R, Scharfenort R, Lonsdorf TB. 2018. Individual differences in fear learning: specificity to traitanxiety beyond other measures of negative affect and mediation via amygdala activation. bioRxiv. DOI: https:// doi.org/10.1101/233528

Sjouwerman R, Lonsdorf TB. 2019. Latency of skin conductance responses across stimulus modalities.

Psychophysiology 56:e13307. DOI: https://doi.org/10.1111/psyp.13307, PMID: 30461024

Spielberger CD, Gorsuch RL, Lushene RE. 1983. Manual for the State-Trait Anxiety Inventory. Consulting Psychologists Press.

Steegen S, Tuerlinckx F, Gelman A, Vanpaemel W. 2016. Increasing transparency through a multiverse analysis. Perspectives on Psychological Science 11:702-712. DOI: https://doi.org/10.1177/1745691616658637, PMID: 27694465

Tabbert K, Merz CJ, Klucken T, Schweckendiek J, Vaitl D, Wolf OT, Stark R. 2011. Influence of contingency awareness on neural, electrodermal and evaluative responses during fear conditioning. Social Cognitive and Affective Neuroscience 6:495-506. DOI: https://doi.org/10.1093/scan/nsq070, PMID: 20693389

Tani H, Tada M, Maeda T, Konishi M, Umeda S, Terasawa Y, Mimura M, Takahashi T, Uchida H. 2019. Comparison of emotional processing assessed with fear conditioning by interpersonal conflicts in patients with depression and schizophrenia. Psychiatry and Clinical Neurosciences 73:116-125. DOI: https://doi.org/10.1111/ pcn.12805, PMID: 30499148

Taylor VA, Roy M, Chang L, Gill LN, Mueller C, Rainville P. 2018. Reduced Fear-Conditioned pain modulation in experienced meditators: a preliminary study. Psychosomatic Medicine 80:799-806. DOI: https://doi.org/10. 1097/PSY.0000000000000634, PMID: 30134359

Tuominen L, Boeke E, DeCross S, Wolthusen RP, Nasr S, Milad M, Vangel M, Tootell R, Holt D. 2019. The relationship of perceptual discrimination to neural mechanisms of fear generalization. Neurolmage 188:445455. DOI: https://doi.org/10.1016/j.neuroimage.2018.12.034, PMID: 30572112

Vervliet B, Craske MG, Hermans D. 2013. Fear extinction and relapse: state of the art. Annual Review of Clinical Psychology 9:215-248. DOI: https://doi.org/10.1146/annurev-clinpsy-050212-185542, PMID: 23537484

Weissgerber TL, Milic NM, Winham SJ, Garovic VD. 2015. Beyond bar and line graphs: time for a new data presentation paradigm. PLOS Biology 13:e1002128. DOI: https://doi.org/10.1371/journal.pbio.1002128, PMID: 25901488

Wendt J, Neubert J, Lindner K, Ernst FD, Homuth G, Weike Al, Hamm AO. 2015. Genetic influences on the acquisition and inhibition of fear. International Journal of Psychophysiology 98:499-505. DOI: https://doi.org/ 10.1016/j.ijpsycho.2014.10.007, PMID: 25455425

Wendt J, Hufenbach MC, König J, Hamm AO. 2020. Effects of verbal instructions and physical threat removal prior to extinction training on the return of conditioned fear. Scientific Reports 10:1202. DOI: https://doi.org/10.1038/ s41598-020-57934-7

Wickham H. 2009. Ggplot2: Elegant Graphics for Data Analysis. Springer-Verlag. DOI: https://doi.org/10.1007/ 978-0-387-98141-3 


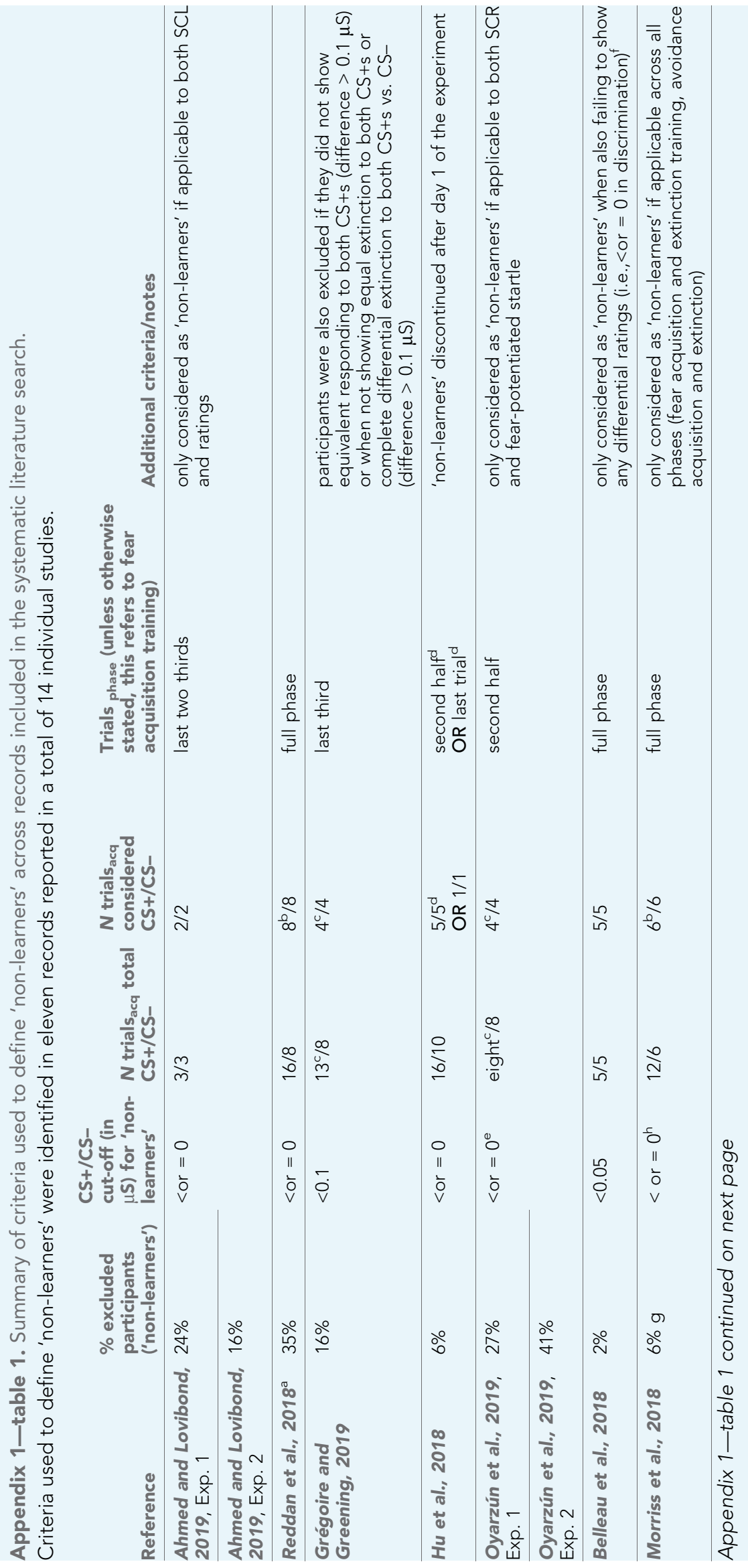




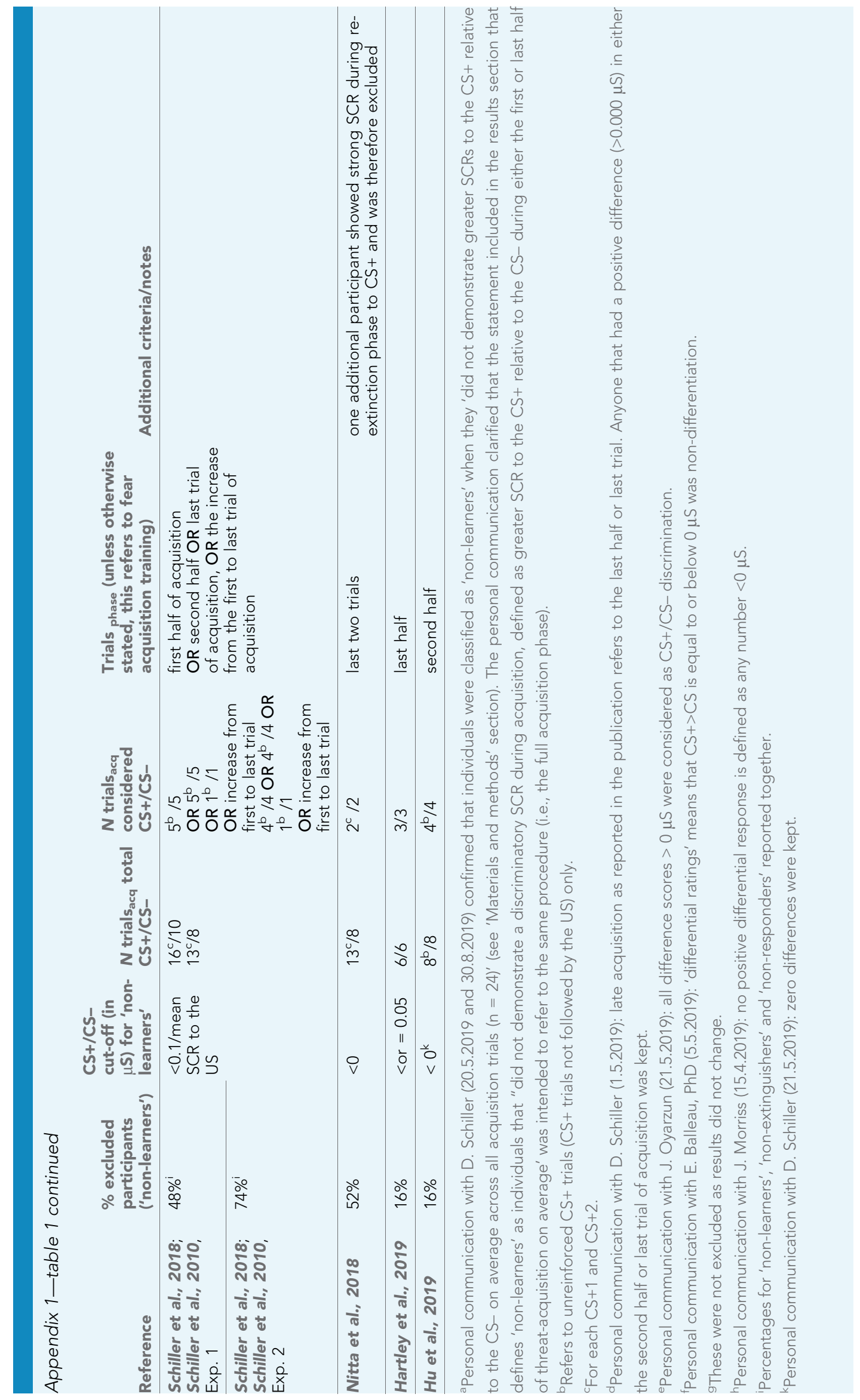




\section{Appendix 1}

\section{Definition of performance-based exclusion of participants ('non-learners') and numbers of participants excluded across studies}

Appendix 1-table 2. Summary of criteria used to define 'non-responders' across records included in the systematic literature search. Fifteen records, reporting a total of 17 studies, were identified.

\begin{tabular}{|c|c|c|c|c|c|}
\hline Record & $\begin{array}{l}\% \text { excluded } \\
\text { participants } \\
\text { ('non- } \\
\text { responders') }\end{array}$ & $\begin{array}{l}\text { Cut-off } \\
\text { (in } \mu \text { S) } \\
\text { for a } \\
\text { valid } \\
\text { SCR }\end{array}$ & $\begin{array}{l}\text { Valid } \\
\text { responses } \\
\text { in at least } \\
\% \text { of trials }\end{array}$ & $\begin{array}{l}\text { Stimulus type (also } \\
\text { referred to as 'trial') } \\
\text { on which the } \\
\text { exclusion is based }\end{array}$ & $\begin{array}{l}\text { Additional } \\
\text { criteria/notes }\end{array}$ \\
\hline $\begin{array}{l}\text { Baeuchl et al., } \\
2019\end{array}$ & $10 \%$ & $>0.01$ & $\geq 66 \%$ & $\mathrm{CXT+}$ & \\
\hline $\begin{array}{l}\text { Tuominen et al., } \\
2019\end{array}$ & $12 \%$ & $>0.05$ & $\geq 13 \%$ & $\mathrm{CS}+$ and $\mathrm{CS}_{-}$ & \\
\hline $\begin{array}{l}\text { Gruss and Keil, } \\
2019\end{array}$ & $11 \%$ & \multicolumn{2}{|c|}{ visual inspection ${ }^{a}$} & $\mathrm{CS}+, \mathrm{CS}-$ and US & \\
\hline $\begin{array}{l}\text { Sjouwerman and } \\
\text { Lonsdorf, } 2019\end{array}$ & $14 \%$ & $\geq 0.02$ & $\begin{array}{l}\text { US: } \geq 67 \% \\
\text { CS: no valid } \\
\text { response in } \\
\text { each CS } \\
\text { modality }\end{array}$ & $\mathrm{CS}+, \mathrm{CS}-$ and US & \\
\hline $\begin{array}{l}\text { Grégoire and } \\
\text { Greening, } 2019\end{array}$ & $8 \%$ & $>0.02$ & $\geq 25 \%^{b}$ & $\mathrm{CS}+$ and $\mathrm{CS}_{-}{ }^{\mathrm{C}}$ & \\
\hline Hu et al., 2018 & $3 \%$ & $\geq 0.02$ & $100 \%$ & $\mathrm{CS}+$ and $\mathrm{CS}_{-}{ }^{\mathrm{C}}$ & $\begin{array}{l}\text { 'non-responders' } \\
\text { discontinued } \\
\text { after day } 1 \text { of the } \\
\text { experiment }\end{array}$ \\
\hline $\begin{array}{l}\text { Oyarzún et al., } \\
\text { 2019, Exp. } 1\end{array}$ & $0 \%$ & \multirow[t]{2}{*}{$\geq 0.02$} & \multirow[t]{2}{*}{$\geq 25 \%$} & \multirow[t]{2}{*}{$\mathrm{CS}{ }^{\mathrm{d}}$ and $\mathrm{CS}_{-}{ }^{\mathrm{c}}$} & \\
\hline $\begin{array}{l}\text { Oyarzún et al., } \\
\text { 2019, Exp. } 2\end{array}$ & $9 \%$ & & & & \\
\hline Tani et al., 2019 & $10 \%$ & $>0.03^{e}$ & $100 \%$ & $\mathrm{CS}+$ & \\
\hline Marin et al., 2019 & $0 \%^{f}$ & $\geq 0.03$ & $\geq 10 \%$ & US & \\
\hline $\begin{array}{l}\text { Taylor et al., } \\
2018\end{array}$ & $5 \%$ & NA & $100 \%$ & motor test ${ }^{9}$ & \\
\hline $\begin{array}{l}\text { Morriss et al., } \\
2018\end{array}$ & $6 \%$ & $>0.03$ & $\geq 90 \%$ & $\mathrm{CS}{ }^{\mathrm{d}}$ and $\mathrm{CS}_{-}{ }^{\mathrm{c}}$ & $\begin{array}{l}\text { only applicable if } \\
\text { true across all } \\
\text { phases/days of } \\
\text { the experiment }\end{array}$ \\
\hline $\begin{array}{l}\text { Schiller et al., } \\
2018 \text {; } \\
\text { Schiller et al., } \\
2010 \text {, Exp. } 1\end{array}$ & $48 \%^{h}$ & \multirow[t]{2}{*}{$\geq 0.02$} & \multirow[t]{2}{*}{$\geq 25 \%$} & \multirow[t]{2}{*}{$\mathrm{CS}_{+}^{\mathrm{d}}$ and $\mathrm{CS}_{-}$} & \\
\hline $\begin{array}{l}\text { Schiller et al., } \\
\text { 2018; } \\
\text { Schiller et al., } \\
\text { 2010, Exp } 2\end{array}$ & $74 \%^{h}$ & & & & \\
\hline
\end{tabular}

Appendix 1-table 2 continued on next page 
Appendix 1-table 2 continued

\begin{tabular}{|c|c|c|c|c|c|}
\hline Record & $\begin{array}{l}\% \text { excluded } \\
\text { participants } \\
\text { ('non- } \\
\text { responders') }\end{array}$ & $\begin{array}{l}\text { Cut-off } \\
\text { (in } \mu \text { S) } \\
\text { for a } \\
\text { valid } \\
\text { SCR }\end{array}$ & $\begin{array}{l}\text { Valid } \\
\text { responses } \\
\text { in at least } \\
\% \text { of trials }\end{array}$ & $\begin{array}{l}\text { Stimulus type (also } \\
\text { referred to as 'trial') } \\
\text { on which the } \\
\text { exclusion is based }\end{array}$ & $\begin{array}{l}\text { Additional } \\
\text { criteria/notes }\end{array}$ \\
\hline $\begin{array}{l}\text { Morriss and van } \\
\text { Reekum, 2019, } \\
\text { Exp. } 1\end{array}$ & $2 \%$ & $>0.03$ & $>90 \%$ & $\mathrm{CS}^{\mathrm{d}}{ }^{\mathrm{a}}$ and $\mathrm{CS}_{-}$ & \\
\hline $\begin{array}{l}\text { Morriss and van } \\
\text { Reekum, 2019, } \\
\text { Exp. } 2\end{array}$ & $2 \%$ & & & & \\
\hline $\begin{array}{l}\text { Hartley et al., } \\
2019\end{array}$ & $6 \%$ & $<0.05^{i}$ & $\geq 33 \%$ & $\mathrm{CS}+$ and $\mathrm{CS}_{-}{ }^{\mathrm{c}}$ & \\
\hline Hu et al., 2019 & $4 \%^{k}$ & $\geq 0.02$ & $100 \%^{k}$ & US & \\
\hline $\begin{array}{l}\text { Leuchs et al., } \\
2019\end{array}$ & $4 \%$ & NA & $\geq 33 \%$ & $\mathrm{CS}+$ and $\mathrm{CS}_{-}{ }^{\mathrm{c}}$ & $\begin{array}{l}\text { only applicable if } \\
\text { true across both } \\
\text { days of the ex- } \\
\text { periment }\end{array}$ \\
\hline
\end{tabular}

aPersonal communication with L. Forest Gruss (29.4.2019): "the determination of non-responders was done, this was done on visual inspection by me through all trials of all individuals. I verified after determining who the lowest, i.e. non-responders were, in the same fashion as the startle non-responders in summing responding over the entire experiment, and this responding falling below a threshold of overall response $(\sim<10 \%)$ AND one individual due to lack of response at the end of the trial to the UCS specifically".

bPersonal communication with S.G. Greening (24.4.2019): "non-responders if more than $75 \%$ of data were missing (i.e., $\mathrm{SCR}<0.02 \mu \mathrm{S}$ ) during the training phase. So, that means, if a participant had at least six trials (out of 24) with measurable SCRs (whatever the condition), we kept them (if the other acquisition criteria were OK, see below). If they had five trials or fewer with measurable GSR, we considered them a non-responder and removed them".

'Personal communications that 'trial' or this statement refers to CS+ and CS- trials: S. Greening (24.4.2019), D. Schiller (1.5.2019), J. Oyarzun (21.5.2019), J. Morriss (15.4.2019), C. Hartley (2.5.2019), V. Spoormaker (18.4.2019).

${ }^{d}$ CS+ unpaired.

ePersonal communication with H. Tani (2.5.2019): only CS+ trials were considered (here as response to the sound or the intrapersonal stimulus).

fPersonal communication with M.-F. Marin (23.4.2019): exclusion criteria were defined, but no participant met these criteria and hence none was excluded.

IPersonal communication with V. Taylor (6.6.2019): clarified that "non-responders' were identified in a "motor test of SCR responding during the preliminary session. Essentially, they had to compress a ball with the right hand with maximal physical force for a few seconds on about 10 trials, which typically elicits quite large SCRs in subjects. Failure to respond to an SCR to all of these trials was considered a non-responder".

hPercentages for 'non-learners', 'non-extinguishers' and 'non-responders' reported together.

'Personal communication with C. Hartley (2.5.2019): clarified that "participants were considered non-responder if they had SCR values of 0 for more than 8 of the 12 trials in acquisition $(<4$ responsive trials)".

$k$ The percentage of 'non-responders' and 'non-learners' was reported together without percentages for each category; personal communication with D. Schiller (21.5.2019): in the paper, it is reported that five individuals 'were excluded due to equipment malfunction $(\mathrm{N}=2)$ or had non-measurable skin conductance response $(S C R)$ to the shock $(N=3)^{\prime \prime}$. It was confirmed that these individuals excluded for non-measurable SCR did not show any responses to any stimulus. 


\section{Appendix 2}

\section{Applying the identified performance-based exclusion criteria to existing data: a case example}

In this case example based on Data set 1 (see main manuscript), we tested whether CS+/CSdiscrimination in SCRs does indeed differ between the different exclusion groups as defined by the cut-offs retrieved from the literature (see Figure 2B). Note that this is somewhat circular as exclusion groups are defined by different SCR CS+/CS- cutoffs, which then are used in an analysis in which differential SCRs are the dependent measure. However, that this is exactly what is sometimes done in the literature (see main manuscript).

Still, this is an important manipulation check to test empirically whether those classified in a group of 'non-learners' in the literature do indeed show no evidence of learning, which would be indicated by comparable SCRs to the CS+ and the CS- (i.e., no significant discrimination). Here, we test this for cumulative exclusion groups. Note that this is only a rough manipulation check, as a non-significant CS+/CS- discrimination effect in the whole group (e.g., those showing a CS+/CS- discrimination $<0.05 \mu \mathrm{S}$ based on raw scores) cannot be taken as evidence that all individuals in this group do not display meaningful or statistically significant CS+/CSdiscrimination. More precisely, half of this group who did not meet the cut-off of $0.05 \mu \mathrm{S}$ in CS +/CS- discrimination do show a negative or zero discrimination score, which may bias the group average score towards non-discrimination. Yet, statistically testing for discrimination within each exclusion group (e.g. specifically in the group showing a discrimination between $>0$ and $<0.05 \mu \mathrm{S}$ ) is not unproblematic.

Appendix 2-table 1. Results of two-tailed t-tests for differences in SCR CS+/CSdiscrimination in Data set 1 for the different cumulative exclusion groups (indicated by the + in the table) based on the criteria identified in the literature with respect to CS+/CS-

discrimination cutoffs (in $\mu \mathrm{S}$ ). For completeness sake and as it is not always clear whether CS+/ CS- discrimination is based on raw or transformed values, we report results based on analyses of both raw (A) and transformed values (B). P-values for these post-hoc tests are Bonferroni corrected.

A) t-tests: CS+/CS- discrimination based on raw values

\begin{tabular}{lllllll}
\hline $\begin{array}{l}\text { Exclusion group } \\
\text { (cumulative) }\end{array}$ & $\begin{array}{l}\text { CS+ } \\
\mathbf{M}(\mathbf{S D})\end{array}$ & $\begin{array}{l}\mathbf{C S} \text { - } \\
\mathbf{M}(\mathbf{S D})\end{array}$ & $\mathbf{d f}$ & $\mathbf{t}$ & $\mathbf{P b o n f \_ c o r r}$ & $\mathbf{d}$ \\
\hline$<0$ & $0.04(0.04)$ & $0.07(0.07)$ & 10 & -2.67 & .140 & 0.81 \\
\hline$+=0$ & $0.02(0.04)$ & $0.03(0.05)$ & 33 & -2.24 & .193 & 0.38 \\
\hline$+>0$ and $<0.05$ & $0.04(0.05)$ & $0.03(0.05)$ & 66 & 2.14 & .219 & 0.26 \\
\hline$+=0.05$ & $0.04(0.05)$ & $0.03(0.05)$ & 70 & 2.88 & .031 & 0.34 \\
\hline$+>0.05$ and $<0.1$ & $0.06(0.06)$ & $0.04(0.05)$ & 88 & 5.87 & .0000005 & 0.62 \\
\hline$+\geq 0.1$ & $0.10(0.10)$ & $0.04(0.06)$ & 115 & 7.87 & $<0.000000001$ & 0.73
\end{tabular}

B) t-tests: CS+/CS- discrimination based on log-transformed and range-corrected values

\begin{tabular}{lllllll}
\hline $\begin{array}{l}\text { Exclusion group } \\
\text { (cumulative) }\end{array}$ & $\begin{array}{l}\text { CS } \\
\mathbf{M}(\text { SD) }\end{array}$ & $\begin{array}{l}\text { CS } \\
\mathbf{M}(\mathbf{S D})\end{array}$ & $\mathbf{d f}$ & $\mathbf{t}$ & $\mathbf{P}_{\text {bonf_corr }}$ & $\mathbf{d}$ \\
\hline$<0$ & $0.09(0.10)$ & $0.13(0.11)$ & 13 & -3.46 & 0.025 & 0.93 \\
\hline$+=0$ & $0.04(0.08)$ & $0.06(0.10)$ & 28 & -2.90 & 0.043 & 0.54 \\
\hline$+>0$ and $<0.05$ & $0.06(0.10)$ & $0.07(0.11)$ & 42 & -0.88 & $>0.999$ & 0.13 \\
\hline$+=0.05$ & $0.07(0.10)$ & $0.07(0.11)$ & 46 & -0.06 & $>0.999$ & 0.01 \\
\hline$+>0.05$ and $<0.1$ & $0.09(0.11)$ & $0.07(0.11)$ & 60 & 2.81 & .040 & 0.36 \\
\hline$+\geq 0.1$ & $0.21(0.19)$ & $0.10(0.11)$ & 115 & 9.56 & $<0.000000001$ & 0.89 \\
\hline
\end{tabular}




\section{Appendix 3}

\section{Exploratory analyses on consistency of classification} ('learners' vs. 'non-learners') across outcome measures and criteria employed

Throughout the main manuscript and particularly in the discussion, we highlight that differential (CS+>CS-) SCRs alone cannot be taken to infer 'learning' (Figure 4-figure supplement 1).

Appendix 3-table 1 provides statistical information on CS+/CS- discrimination in fear ratings in (cumulative) exclusion groups as defined by $\mathrm{CS}+/ \mathrm{CS}-$ discrimination in SCRs.

Appendix 3-table 1. CS+/CS- discrimination in fear ratings in (cumulative) exclusion groups (indicated by the + in the table) as defined by CS+/CS- discrimination in SCRs (based on raw scores).

\begin{tabular}{lllllll} 
Exclusion group (cumulative) & $\begin{array}{l}\text { CS } \\
\mathbf{M}(\text { SD) }\end{array}$ & $\begin{array}{l}\text { CS } \\
\mathbf{M}(\text { SD) }\end{array}$ & $\mathbf{d f}$ & $\mathbf{t}$ & P bonf_corr & $\boldsymbol{d}$ \\
\hline$<0$ & $15.8(8.94)$ & $2.45(4.70)$ & 10 & 5.37 & 0.002 & 1.62 \\
\hline$+=0$ & $16.6(7.73)$ & $3.15(5.82)$ & 31 & 9.69 & $<0.000000001$ & 1.71 \\
\hline$+>0$ and $<0.05$ & $16.2(7.37)$ & $3.06(5.86)$ & 64 & 12.8 & $<0.000000001$ & 1.59 \\
\hline$+=0.05$ & $16.3(7.26)$ & $2.96(5.75)$ & 67 & 13.4 & $<0.000000001$ & 1.62 \\
\hline$+>0.05$ and $<0.1$ & $16.5(6.97)$ & $2.94(5.47)$ & 84 & 16.0 & $<0.000000001$ & 1.74 \\
\hline$+>=0.1$ & $17.3(6.64)$ & $3.08(5.04)$ & 110 & 20.2 & $<0.000000001$ & 1.92 \\
\hline
\end{tabular}




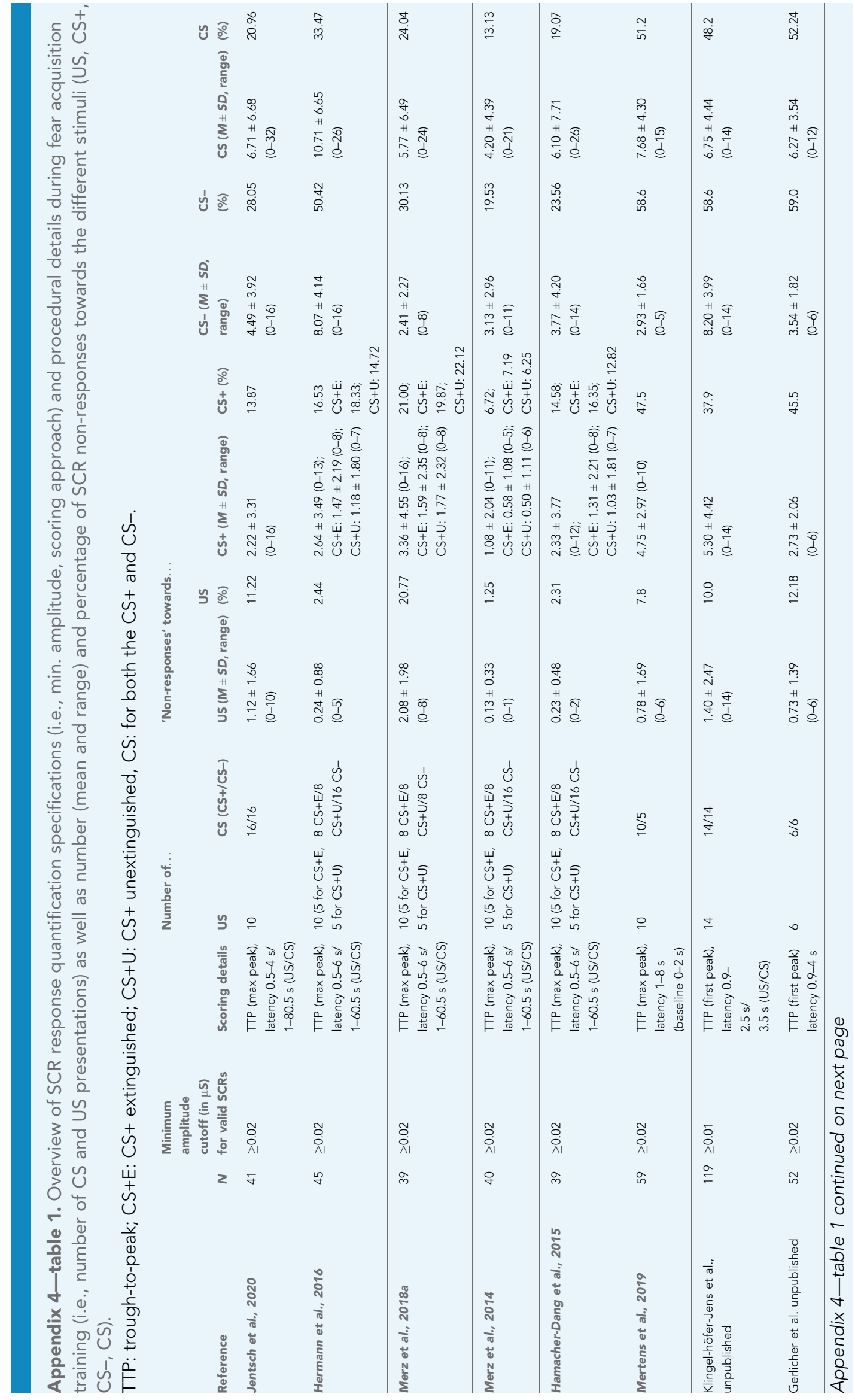




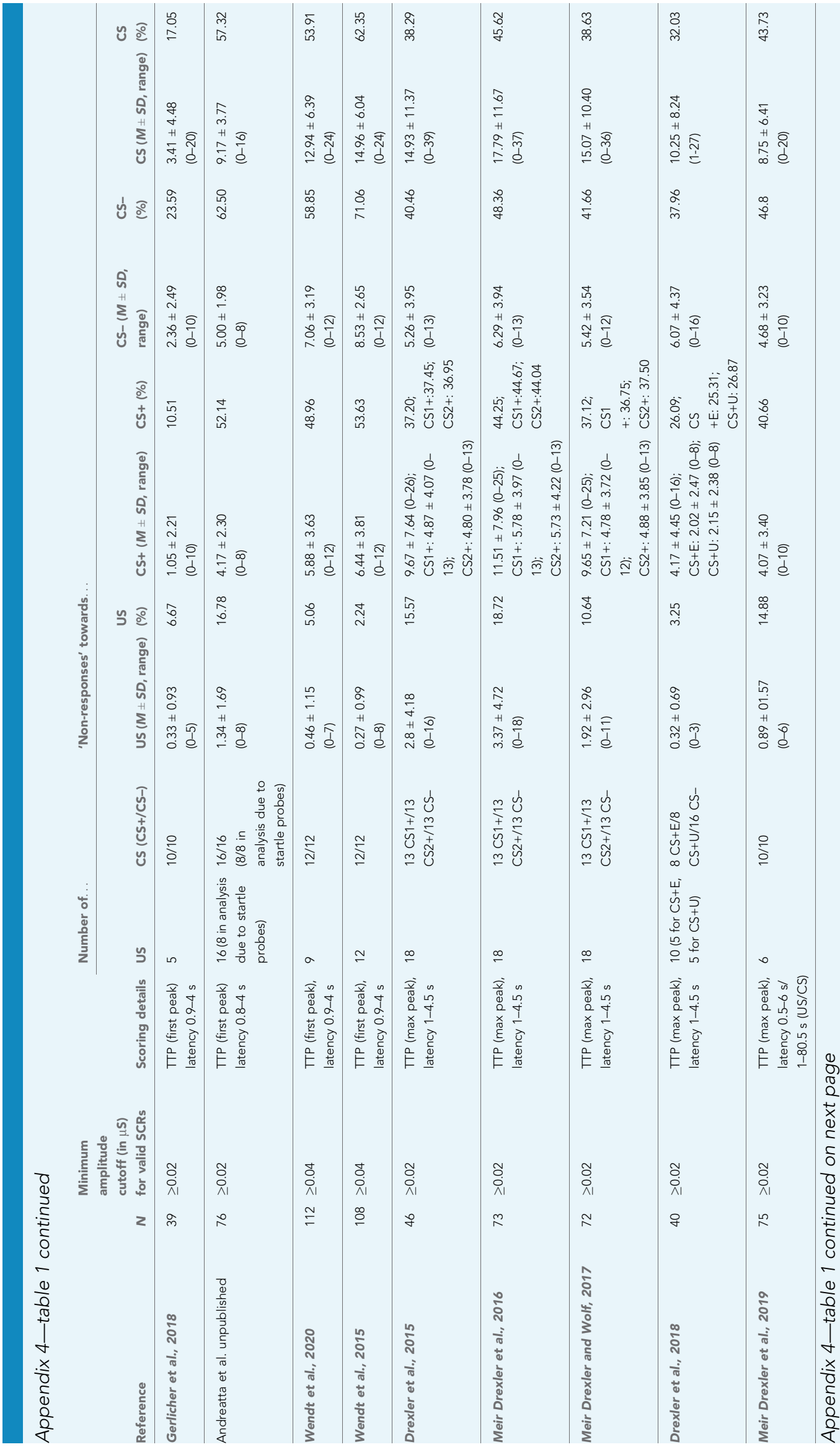




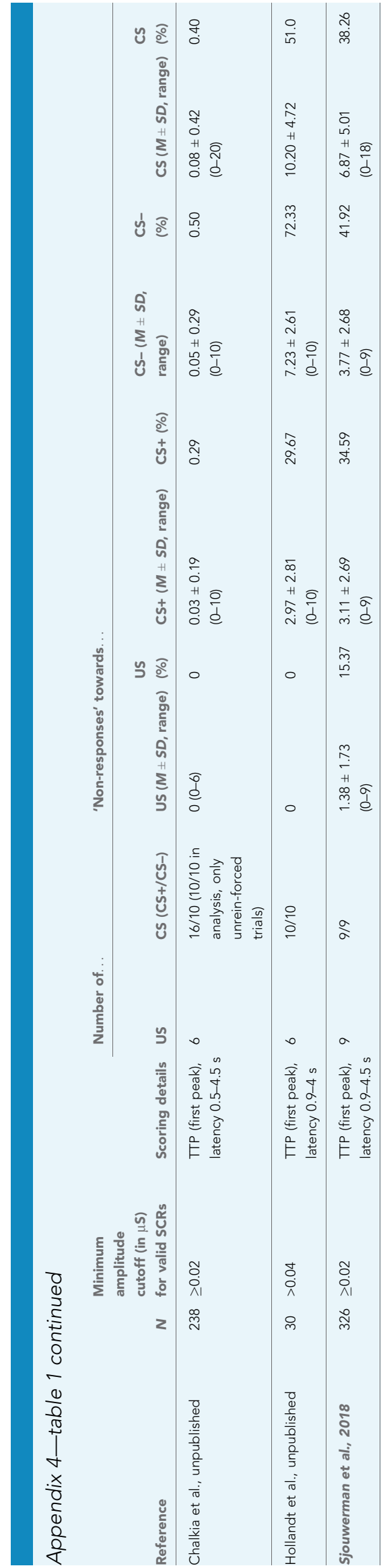




\section{Appendix 4}

\section{Definition of 'non-responders 'and amount of participants excluded across studies}

In the main manuscript, we discuss different frequencies of 'non-responding' to different experimental stimuli (e.g., US, CS+ and CS- in isolation or in combination), which inherently lead to different exclusion frequencies when classifying 'non-responders' on the basis of different types of stimuli. As there is little empirical work on the frequency of 'non-responses' to the US, CSs (i.e., CS+ and CS-) and CS+ only to base recommendations on, we compiled this information across 20 different data sets (see Appendix 4-table 1), including information on SCR response quantification specifications (i.e., minimum amplitude, scoring approach) and procedural details during fear acquisition training (i.e., number of CS and US presentations). These data sets were provided by different co-authors involved in this manuscript.

In addition, Appendix 4-table 2 provides information on the number and percentage of individuals in a sample showing SCR 'non-responses' to a certain number of US presentations during fear acquisition training as well as mean number and percentage of CS responses (CS refers to the CS+ and CS- combined) in these individuals to guide the development of empirically based criteria to define SCR 'non-responders'.

Appendix 4-table 2. Number and percentage of individuals in a sample showing SCR nonresponses to a certain number of US presentations during fear acquisition training (exemplarily for one to eight USs ${ }^{\#}$ ), as well as mean number of and percentage of CS responses (CS refers to the CS+ and CS- combined) in these individuals. "Here only up to eight USs are included as eight is half of the maximum number of US presentations in the samples included here.

a) $\boldsymbol{n}$ (\%) of individuals with $0,1,2,3,4,5,6,7$, and 8 SCRs towards the US. b) $M(\%)$ of valid CS responses for these individuals.

\begin{tabular}{|c|c|c|c|c|c|c|c|c|c|}
\hline \multirow[b]{2}{*}{ Reference } & \\
\hline & o US & 1 US & 2 US & 3 US & 4 US & 5 US & 6 US & 7 US & 8 US \\
\hline Jentsch et al., 2020 & $\begin{array}{l}\text { a) } 1 \\
(2.4 \%) \text { b) } \\
0(0 \%)\end{array}$ & $\begin{array}{l}\text { a) } 0(0 \%) \\
\text { b) NA }\end{array}$ & $\begin{array}{l}\text { a) } 0(0 \%) \\
\text { b) NA }\end{array}$ & $\begin{array}{l}\text { a) } 0(0 \%) \\
\text { b) NA }\end{array}$ & $\begin{array}{l}\text { a) } 0(0 \%) \\
\text { b) NA }\end{array}$ & $\begin{array}{l}\text { a) } 0(0 \%) \text { b) } \\
\text { NA }\end{array}$ & $\begin{array}{l}\text { a) } 0(0 \%) \\
\text { b) } \mathrm{NA}\end{array}$ & $\begin{array}{l}\text { a) } 2 \\
(4.9 \%) \text { b) } \\
27.5 \\
(85.9 \%)\end{array}$ & $\begin{array}{l}\text { a) } 7 \\
(17.1 \%) \text { b) } \\
25.4 \\
(79.5 \%)\end{array}$ \\
\hline $\begin{array}{l}\text { Hermann et al., } \\
2016\end{array}$ & $\begin{array}{l}\text { a) } 0(0 \%) \\
\text { b) NA }\end{array}$ & $\begin{array}{l}\text { a) } 0(0 \%) \\
\text { b) NA }\end{array}$ & $\begin{array}{l}\text { a) } 0(0 \%) \\
\text { b) NA }\end{array}$ & $\begin{array}{l}\text { a) } 0(0 \%) \\
\text { b) NA }\end{array}$ & $\begin{array}{l}\text { a) } 0(0 \%) \\
\text { b) NA }\end{array}$ & $\begin{array}{l}\text { a) } 1(2 \%) \text { b) } \\
12(37.5 \%)\end{array}$ & $\begin{array}{l}\text { a) } 0(0 \%) \\
\text { b) NA }\end{array}$ & $\begin{array}{l}\text { a) } 1(2 \%) \\
\text { b) } 14 \\
(43.7 \%)\end{array}$ & $\begin{array}{l}\text { a) } 0(0 \%) \\
\text { b) NA }\end{array}$ \\
\hline Merz et al., 2018a & $\begin{array}{l}\text { a) } 0(0 \%) \\
\text { b) NA }\end{array}$ & $\begin{array}{l}\text { a) } 0(0 \%) \\
\text { b) NA }\end{array}$ & $\begin{array}{l}\text { a) } 1 \\
(2.6 \%) \text { b) } \\
23.0 \\
(95.8 \%)\end{array}$ & $\begin{array}{l}\text { a) } 0(0 \%) \\
\text { b) NA }\end{array}$ & $\begin{array}{l}\text { a) } 2 \\
(5.1 \%) \text { b) } \\
20.0 \\
(83.3 \%)\end{array}$ & $\begin{array}{l}\text { a) } 3(7.7 \%) \\
\text { b) } 23.0 \\
\text { (95.8\%) }\end{array}$ & $\begin{array}{l}\text { a) } 1(2.6 \%) \\
\text { b) } 21.0 \\
(87.5 \%)\end{array}$ & $\begin{array}{l}\text { a) } 5 \\
\text { (12.8\%) } \\
\text { b) } 21.4 \\
(89.1 \%)\end{array}$ & $\begin{array}{l}\text { a) } 9 \\
(23.1 \%) \text { b) } \\
21.6 \\
(85.6 \%)\end{array}$ \\
\hline Merz et al., 2014 & $\begin{array}{l}\text { a) } 0(0 \%) \\
\text { b) NA }\end{array}$ & $\begin{array}{l}\text { a) } 0(0 \%) \\
\text { b) NA }\end{array}$ & $\begin{array}{l}\text { a) } 0(0 \%) \\
\text { b) NA }\end{array}$ & $\begin{array}{l}\text { a) } 0(0 \%) \\
\text { b) NA }\end{array}$ & $\begin{array}{l}\text { a) } 0(0 \%) \\
\text { b) NA }\end{array}$ & $\begin{array}{l}\text { a) } 0(0 \%) \text { b) } \\
\text { NA }\end{array}$ & $\begin{array}{l}\text { a) } 0(0 \%) \\
\text { b) NA }\end{array}$ & $\begin{array}{l}\text { a) } 0(0 \%) \\
\text { b) NA }\end{array}$ & $\begin{array}{l}\text { a) } 0(0 \%) \\
\text { b) NA }\end{array}$ \\
\hline $\begin{array}{l}\text { Hamacher- } \\
\text { Dang et al., } 2015\end{array}$ & $\begin{array}{l}\text { a) } 0(0 \%) \\
\text { b) NA }\end{array}$ & $\begin{array}{l}\text { a) } 0(0 \%) \\
\text { b) NA }\end{array}$ & $\begin{array}{l}\text { a) } 0(0 \%) \\
\text { b) NA }\end{array}$ & $\begin{array}{l}\text { a) } 0(0 \%) \\
\text { b) NA }\end{array}$ & $\begin{array}{l}\text { a) } 0(0 \%) \\
\text { b) NA }\end{array}$ & $\begin{array}{l}\text { a) } 0(0 \%) \text { b) } \\
\text { NA }\end{array}$ & $\begin{array}{l}\text { a) } 0(0 \%) \\
\text { b) NA }\end{array}$ & $\begin{array}{l}\text { a) } 0(0 \%) \\
\text { b) NA }\end{array}$ & $\begin{array}{l}\text { a) } 1(3 \%) \\
\text { b) } 24 \\
(75.0 \%)\end{array}$ \\
\hline Mertens et al., 2019 & $\begin{array}{l}\text { a) } 0(0 \%) \\
\text { b) NA }\end{array}$ & $\begin{array}{l}\text { a) } 0(0 \%) \\
\text { b) NA }\end{array}$ & $\begin{array}{l}\text { a) } 0(0 \%) \\
\text { b) NA }\end{array}$ & $\begin{array}{l}\text { a) } 0(0 \%) \\
\text { b) NA }\end{array}$ & $\begin{array}{l}\text { a) } 4 \\
\text { (6.78\%) b) } \\
1.75 \\
(11.67 \%)\end{array}$ & $\begin{array}{l}\text { a) } 0(0 \%) \text { b) } \\
\text { NA }\end{array}$ & $\begin{array}{l}\text { a) } 2 \\
(3.39 \%) \text { b) } \\
3.5 \\
(23.33 \%)\end{array}$ & $\begin{array}{l}\text { a) } 2 \\
\text { (3.39\%) } \\
\text { b) } 9 \\
\text { (60\%) }\end{array}$ & $\begin{array}{l}\text { a) } 0(0 \%) \\
\text { b) NA }\end{array}$ \\
\hline $\begin{array}{l}\text { Klingelhöfer-Jens } \\
\text { et al., unpublished }\end{array}$ & $\begin{array}{l}\text { a) } 2 \\
(1.68 \%) \\
\text { b) } 0(0 \%)\end{array}$ & $\begin{array}{l}\text { a) } 0(0 \%) \\
\text { b) NA }\end{array}$ & $\begin{array}{l}\text { a) } 1 \\
\text { (0.84\%) } \\
\text { b) } 10 \\
(35.7 \%)\end{array}$ & $\begin{array}{l}\text { a) } 0(0 \%) \\
\text { b) NA }\end{array}$ & $\begin{array}{l}\text { a) } 0(0 \%) \\
\text { b) NA }\end{array}$ & $\begin{array}{l}\text { a) } 0(0 \%) \text { b) } \\
\text { NA }\end{array}$ & $\begin{array}{l}\text { a) } 1 \\
(0.84 \%) \text { b) } \\
1(3.57 \%)\end{array}$ & $\begin{array}{l}\text { a) } 2 \\
\text { (1.68\%) } \\
\text { b) } 2 \\
(7.14 \%)\end{array}$ & $\begin{array}{l}\text { a) } 1 \\
(0.84 \%) \text { b) } \\
0(0 \%)\end{array}$ \\
\hline
\end{tabular}

Appendix 4-table 2 continued on next page 
Appendix 4-table 2 continued

a) $n$ (\%) of individuals with $0,1,2,3,4,5,6,7$, and 8 SCRs towards the US. b) $M(\%)$ of valid CS responses for these individuals.

\begin{tabular}{|c|c|c|c|c|c|c|c|c|c|}
\hline \multirow[b]{2}{*}{ Reference } & & & & & & & & & \\
\hline & o US & 1 US & 2 US & 3 US & 4 US & 5 US & 6 US & 7 US & 8 US \\
\hline $\begin{array}{l}\text { Gerlicher et al., un- } \\
\text { published }\end{array}$ & $\begin{array}{l}\text { a) } 0(0 \%) \\
\text { b) } \mathrm{NA}\end{array}$ & $\begin{array}{l}\text { a) } 0(0 \%) \\
\text { b) NA }\end{array}$ & $\begin{array}{l}\text { a) } 0(0 \%) \\
\text { b) NA }\end{array}$ & $\begin{array}{l}\text { a) } 3 \\
(5.77 \%) \\
\text { b) } 4 \\
(33.33 \%)\end{array}$ & $\begin{array}{l}\text { a) } 5 \\
(9.62 \%) \text { b) } \\
4.8(40 \%)\end{array}$ & $\begin{array}{l}\text { a) } 7 \\
(13.46 \%) \\
\text { b) } 6.7 \\
(55.91 \%)\end{array}$ & $\begin{array}{l}\text { a) } 35 \\
\text { (67.31\%) } \\
\text { b) } 6.15 \\
\text { (51.25\%) }\end{array}$ & NA & NA \\
\hline $\begin{array}{l}\text { Gerlicher et al., } \\
2018\end{array}$ & $\begin{array}{l}\text { a) } 1 \\
(2.56 \%) \\
\text { b) } 0(0 \%)\end{array}$ & $\begin{array}{l}\text { a) } 0(0 \%) \\
\text { b) NA }\end{array}$ & $\begin{array}{l}\text { a) } 0(0 \%) \\
\text { b) NA }\end{array}$ & $\begin{array}{l}\text { a) } 2 \\
\text { (5.13\%) } \\
\text { b) } 19.5 \\
\text { (97.5\%) }\end{array}$ & $\begin{array}{l}\text { a) } 4 \\
\text { (10.26\%) } \\
\text { b) } 17.5 \\
\text { (87.50\%) }\end{array}$ & $\begin{array}{l}\text { a) } 32 \\
(82.05 \%) \\
\text { b) } 16.81 \\
(84.05 \%)\end{array}$ & NA & NA & NA \\
\hline Wendt et al., 2020 & $\begin{array}{l}\text { a) } 0(0 \%) \\
\text { b) NA }\end{array}$ & $\begin{array}{l}\text { a) } 0(0 \%) \\
\text { b) NA }\end{array}$ & $\begin{array}{l}\text { a) } 1 \\
(0.9 \%) \text { b) } \\
18(75 \%)\end{array}$ & $\begin{array}{l}\text { a) } 1 \\
(0.9 \%) \text { b) } \\
24(100 \%)\end{array}$ & $\begin{array}{l}\text { a) } 1 \\
(0.9 \%) \text { b) } \\
0(0 \%)\end{array}$ & $\begin{array}{l}\text { a) } 0(0 \%) \text { b) } \\
\text { NA }\end{array}$ & $\begin{array}{l}\text { a) } 2(1.8 \%) \\
\text { b) } 12 \\
\text { (50\%) }\end{array}$ & $\begin{array}{l}\text { a) } 8 \\
(7.1 \%) \text { b) } \\
13.13 \\
(54.69 \%)\end{array}$ & $\begin{array}{l}\text { a) } 11 \\
\text { (9.9\%) b) } \\
11.09 \\
(46.21 \%)\end{array}$ \\
\hline Wendt et al., 2015 & $\begin{array}{l}\text { a) } 0(0 \%) \\
\text { b) NA }\end{array}$ & $\begin{array}{l}\text { a) } 0(0 \%) \\
\text { b) NA }\end{array}$ & $\begin{array}{l}\text { a) } 0(0 \%) \\
\text { b) } \mathrm{NA}\end{array}$ & $\begin{array}{l}\text { a) } 0(0 \%) \\
\text { b) NA }\end{array}$ & $\begin{array}{l}\text { a) } 1 \\
(0.9 \%) \text { b) } \\
18(75 \%)\end{array}$ & $\begin{array}{l}\text { a) } 0(0 \%) \text { b) } \\
\text { NA }\end{array}$ & $\begin{array}{l}\text { a) } 0(0 \%) \\
\text { b) } \mathrm{NA}\end{array}$ & $\begin{array}{l}\text { a) } 1 \\
(0.9 \%) \text { b) } \\
17 \\
(70.83 \%)\end{array}$ & $\begin{array}{l}\text { a) } 0(0 \%) \\
\text { b) NA }\end{array}$ \\
\hline Drexler et al., 2015 & $\begin{array}{l}\text { a) } 0(0 \%) \\
\text { b) NA }\end{array}$ & $\begin{array}{l}\text { a) } 0(0 \%) \\
\text { b) NA }\end{array}$ & $\begin{array}{l}\text { a) } 2 \\
(4.3 \%) \text { b) } \\
0.5 \\
(1.28 \%)\end{array}$ & $\begin{array}{l}\text { a) } 1 \\
(2.2 \%) \text { b) } \\
0.0(0.0 \%)\end{array}$ & $\begin{array}{l}\text { a) } 0(0 \%) \\
\text { b) NA }\end{array}$ & $\begin{array}{l}\text { a) } 0(0 \%) \text { b) } \\
\text { NA }\end{array}$ & $\begin{array}{l}\text { a) } 0(0 \%) \\
\text { b) NA }\end{array}$ & $\begin{array}{l}\text { a) } 1 \\
(2.2 \%) \text { b) } \\
7.0 \\
(17.94 \%)\end{array}$ & $\begin{array}{l}\text { a) } 0(0 \%) \\
\text { b) } N A\end{array}$ \\
\hline $\begin{array}{l}\text { Meir Drexler et al., } \\
2016\end{array}$ & $\begin{array}{l}\text { a) } 1 \\
(1.4 \%) \text { b) } \\
29.00 \\
(74.35 \%)\end{array}$ & $\begin{array}{l}\text { a) } 0(0 \%) \\
\text { b) NA }\end{array}$ & $\begin{array}{l}\text { a) } 2 \\
(2.7 \%) \text { b) } \\
2.0 \\
(5.12 \%)\end{array}$ & $\begin{array}{l}\text { a) } 1 \\
(1.4 \%) \text { b) } \\
9.0 \\
(23.07 \%)\end{array}$ & $\begin{array}{l}\text { a) } 1 \\
(1.4 \%) \text { b) } \\
2.0 \\
(5.12 \%)\end{array}$ & $\begin{array}{l}\text { a) } 1(1.4 \%) \\
\text { b) } 3.0 \\
\text { (7.69\%) }\end{array}$ & $\begin{array}{l}\text { a) } 0(0 \%) \\
\text { b) NA }\end{array}$ & $\begin{array}{l}\text { a) } 4 \\
(5.5 \%) \text { b) } \\
5.0 \\
(12.82 \%)\end{array}$ & $\begin{array}{l}\text { a) } 2 \\
\text { (2.7\%) b) } \\
6.50 \\
(16.66 \%)\end{array}$ \\
\hline $\begin{array}{l}\text { Meir Drexler and } \\
\text { Wolf, } 2017\end{array}$ & $\begin{array}{l}\text { a) } 0(0 \%) \\
\text { b) NA }\end{array}$ & $\begin{array}{l}\text { a) } 0(0 \%) \\
\text { b) NA }\end{array}$ & $\begin{array}{l}\text { a) } 0(0 \%) \\
\text { b) } \mathrm{NA}\end{array}$ & $\begin{array}{l}\text { a) } 0(0 \%) \\
\text { b) NA }\end{array}$ & $\begin{array}{l}\text { a) } 0(0 \%) \\
\text { b) NA }\end{array}$ & $\begin{array}{l}\text { a) } 0(0 \%) \text { b) } \\
\text { NA }\end{array}$ & $\begin{array}{l}\text { a) } 0(0 \%) \\
\text { b) NA }\end{array}$ & $\begin{array}{l}\text { a) } 1 \\
(1.4 \%) \text { b) } \\
5.0 \\
(12.82 \%)\end{array}$ & $\begin{array}{l}\text { a) } 1 \\
(1.4 \%) \text { b) } \\
5.0 \\
(12.82 \%)\end{array}$ \\
\hline Drexler et al., 2018 & $\begin{array}{l}\text { a) } 0(0 \%) \\
\text { b) NA }\end{array}$ & $\begin{array}{l}\text { a) } 0(0 \%) \\
\text { b) NA }\end{array}$ & $\begin{array}{l}\text { a) } 0(0 \%) \\
\text { b) NA }\end{array}$ & $\begin{array}{l}\text { a) } 0(0 \%) \\
\text { b) NA }\end{array}$ & $\begin{array}{l}\text { a) } 0(0 \%) \\
\text { b) NA }\end{array}$ & $\begin{array}{l}\text { a) } 0(0 \%) \text { b) } \\
\text { NA }\end{array}$ & $\begin{array}{l}\text { a) } 0(0 \%) \\
\text { b) NA }\end{array}$ & $\begin{array}{l}\text { a) } 1 \\
(2.5 \%) b) \\
8(25 \%)\end{array}$ & $\begin{array}{l}\text { a) } 2 \\
\text { (5.0\%) b) } \\
12.5 \\
(39.06 \%)\end{array}$ \\
\hline $\begin{array}{l}\text { Meir Drexler et al., } \\
2019\end{array}$ & $\begin{array}{l}\text { a) } 3 \\
(4.0 \%) \text { b) } \\
0.33 \\
(1.66 \%)\end{array}$ & $\begin{array}{l}\text { a) } 1 \\
(1.3 \%) \text { b) } \\
1(5.0 \%)\end{array}$ & $\begin{array}{l}\text { a) } 4 \\
\text { (5.3\%) b) } \\
4.25 \\
(21.25 \%)\end{array}$ & $\begin{array}{l}\text { a) } 2 \\
(2.7 \%) \text { b) } \\
3.0 \\
(15.0 \%)\end{array}$ & $\begin{array}{l}\text { a) } 3 \\
(4.0 \%) \text { b) } \\
1.33 \\
(6.66 \%)\end{array}$ & $\begin{array}{l}\text { a) } 19 \\
(25.3 \%) \text { b) } \\
12.63 \\
(63.15 \%)\end{array}$ & $\begin{array}{l}\text { a) } 43 \\
\text { (57.3\%) b) } \\
13.21 \\
(66.04 \%)\end{array}$ & $\begin{array}{l}\text { a) } 0(0 \%) \\
\text { b) NA }\end{array}$ & $\begin{array}{l}\text { a) } 0(0 \%) \\
\text { b) NA }\end{array}$ \\
\hline $\begin{array}{l}\text { Chalkia et al., un- } \\
\text { published }\end{array}$ & $\begin{array}{l}\text { a) } 0(0 \%) \\
\text { b) NA }\end{array}$ & $\begin{array}{l}\text { a) } 0(0 \%) \\
\text { b) NA }\end{array}$ & $\begin{array}{l}\text { a) } 0(0 \%) \\
\text { b) NA }\end{array}$ & $\begin{array}{l}\text { a) } 0(0 \%) \\
\text { b) NA }\end{array}$ & $\begin{array}{l}\text { a) } 0(0 \%) \\
\text { b) NA }\end{array}$ & $\begin{array}{l}\text { a) } 0(0 \%) \text { b) } \\
\text { NA }\end{array}$ & $\begin{array}{l}\text { a) } 238 \\
(100 \%) \text { b) } \\
19.92 \\
(99.6 \%)\end{array}$ & $\begin{array}{l}\text { a) } 0(0 \%) \\
\text { b) NA }\end{array}$ & $\begin{array}{l}\text { a) } 0(0 \%) \\
\text { b) NA }\end{array}$ \\
\hline $\begin{array}{l}\text { Hollandt } \\
\text { et al., unpublished }\end{array}$ & $\begin{array}{l}\text { a) } 0(0 \%) \\
\text { b) NA }\end{array}$ & $\begin{array}{l}\text { a) } 0(0 \%) \\
\text { b) NA }\end{array}$ & $\begin{array}{l}\text { a) } 0(0 \%) \\
\text { b) } \mathrm{NA}\end{array}$ & $\begin{array}{l}\text { a) } 0(0 \%) \\
\text { b) NA }\end{array}$ & $\begin{array}{l}\text { a) } 0(0 \%) \\
\text { b) } \mathrm{NA}\end{array}$ & $\begin{array}{l}\text { a) } 0(0 \%) \text { b) } \\
\text { NA }\end{array}$ & $\begin{array}{l}\text { a) } 0(0 \%) \\
\text { b) NA }\end{array}$ & NA & NA \\
\hline $\begin{array}{l}\text { Sjouwerman et al., } \\
2018\end{array}$ & $\begin{array}{l}\text { a) } 4 \\
(1.23 \%) \\
\text { b) } 0.5 \\
\text { (2.78\%) }\end{array}$ & $\begin{array}{l}\text { a) } 2 \\
\text { (0.61\%) } \\
\text { b) } 2.5 \\
(13.89 \%)\end{array}$ & $\begin{array}{l}\text { a) } 4 \\
(1.23 \%) \\
\text { b) } 4.13 \\
(22.92 \%)\end{array}$ & $\begin{array}{l}\text { a) } 2 \\
\text { (0.61\%) } \\
\text { b) } 7.25 \\
(40.28 \%)\end{array}$ & $\begin{array}{l}\text { a) } 0(0 \%) \\
\text { b) NA }\end{array}$ & $\begin{array}{l}\text { a) } 0(0 \%) \text { b) } \\
\text { NA }\end{array}$ & $\begin{array}{l}\text { a) } 0(0 \%) \\
\text { b) } \mathrm{NA}\end{array}$ & $\begin{array}{l}\text { a) } 0(0 \%) \\
\text { b) NA }\end{array}$ & $\begin{array}{l}\text { a) } 0(0 \%) \\
\text { b) NA }\end{array}$ \\
\hline
\end{tabular}

